\title{
Sinopsis actualizada de Aristolochia (Aristolochiaceae, Piperales) en Panamá
}

\section{An updated synopsis of Aristolochia (Aristolochiaceae, Piperales) in Panama}

\author{
Favio González1 (10, Natalia Pabón-Mora²,3 (1)
}

1 Universidad Nacional de Colombia, Facultad de Ciencias, Instituto de Ciencias Naturales, Sede Bogotá, Colombia.

2 Universidad de Antioquia, Instituto de Biología, Medellín, Colombia.

3 Autor para la correspondencia: lucia.pabon@udea.edu.co

Citar como:

González, F. y N. Pabón-Mora. 2018. Sinopsis actualizada de Aristolochia (Aristolochiaceae: Piperales) en Panamá. Acta Botanica Mexicana 122: 109140. DOI: http://dx.doi.org/10.21829/ abml22.2018.1249

Recibido: 9 de mayo de 2017

Revisado: 21 de junio de 2017

Aceptado: 25 de septiembre de 2017.

Primero en línea: 11 de noviembre de 2017

Publicado: 1 de enero de 2018.

DOI:

http://dx.doi.org/10.21829/abm122.2018.1249

\section{Resumen:}

Antecedentes y Objetivos: Se revisa la taxonomía de las especies panameñas de Aristolochia 57 años después del primer tratamiento del género para la Flora de Panamá. Se actualizan y discuten las novedades taxonómicas, nomenclaturales y corológicas de las especies que se encuentran en Panamá con respecto a la clasificación infragenérica actual.

Métodos: Se revisaron los ejemplares de Aristolochia en 35 herbarios, incluidas colecciones efectuadas por el autor principal del trabajo. También se consultaron los ejemplares tipo disponibles en JSTOR Global Plants. Se presenta una clave de identificación y una diagnosis de los grupos infragenéricos y de las especies, 12 de las cuales son ilustradas con fotografías.

Resultados clave: Cuatro de las 13 especies reportadas para el tratamiento de la Flora de Panamá (Aristolochia arborescens, $A$. costaricensis, A. sylvicola y A. veraguensis) se encuentran actualmente subordinadas como sinónimos. En total se reportan 16 especies, dos de ellas (A. cruenta y A. trilabiata) confirmadas como nuevos registros para Panamá. Aristolochia trilabiata, revalidado aquí en reemplazo de $A$. didyma, constituye el primer reporte de la especie en Mesoamérica. Se revalidan A. schippii, A. sprucei y A. surinamensis, recientemente subordinadas a las sinonimias de $A$. leuconeura, $A$. constricta y $A$. trilobata, respectivamente. Además, $A$. pfeiferi y A. translucida son confirmadas como sinónimos de A. tonduzii, y A. gorgona y A. securidata como sinónimos de $A$. grandiflora y $A$. sprucei, respectivamente. Un total de 13 lectotipos son aquí designados. Finalmente, se discute la presencia de $A$. constricta, $A$. gigantea y $A$. nummularifolia en Panamá. Conclusiones: Las especies de Panamá pertenecen a dos de los tres subgéneros de Aristolochia: A. panamensis, la única especie endémica de Panamá, marca el límite más austral del subgénero Siphisia en el Nuevo Mundo. Las 15 especies restantes pertenecen al subgénero Aristolochia, series Hexandrae (11 spp.) y Thyrsicae (4 spp.).

Palabras clave: biodiversidad, Flora de Panamá, Flora Mesoamericana, Flora Neotrópica, tipificación.

\section{ABSTRACT:}

Background and Aims: The taxonomy of the Panamanian species of Aristolochia is revised 57 years after the first treatment of the genus for the Flora of Panama. The taxonomic, nomenclatural and chorological novelties of the species present in Panama are updated and discussed with respect to the current infrageneric classification.

Methods: Specimens of Aristolochia deposited in 35 herbaria, including specimens collected by the senior author. The type specimens available in JSTOR Global Plants were also examined. A key to the infrageneric groups and species (12 of which are illustrated by photographies) is included.

Key results: Four of the 13 species reported in the treatment for the Flora of Panama (Aristolochia arborescens, $A$. costaricensis, $A$. sylvicola and $A$. veraguensis) are currently reduced as synonyms. A total of 16 species are here reported, two of which (A. cruenta and A. trilabiata) are confirmed as new records for Panama. Aristolochia trilabiata, resurrected here to replace A. didyma, is the first report of this species in Mesoamerica. Here we revalidate Aristolochia schippii, A. sprucei and A. surinamensis, recently reduced as synonyms of $A$. leuconeura, A. constricta and A. trilobata, respectively. In addition, A. pfeiferi and A. translucida are both confirmed as synonyms of $A$. tonduzii, and $A$. gorgona and $A$. securidata as synonyms of $A$. grandiflora and $A$. sprucei, respectively. A total of 13 lectotypes are here designated. Finally, the presence of A. constricta, A. gigantea and A. nummularifolia in Panama is discussed.

Conclusions: The Panamanian species of Aristolochia belong to two of the three subgenera: A. panamensis, the only species endemic to Panama, marks the southernmost limit of subgenus Siphisia in the New World. The remaining 15 species belong to the subgenus Aristolochia, series Hexandrae (11 spp.) and Thyrsicae (4 spp.).

Key words: biodiversity, Flora Mesoamericana, Flora Neotropica, Flora of Panama, typification. 


\section{INTRODUCCIÓN}

Las Aristolochiaceae están representadas en el Neotrópico únicamente por el género Aristolochia L. Con aproximadamente 550 especies, Aristolochia es el género más diversificado y el más ampliamente distribuido de la familia. La distribución global de Aristolochia incluye las franjas tropicales, subtropicales y templadas de todos los continentes, aunque se estima que $75 \%$ de las especies se encuentra en las Américas (González et al., 2015). El género ha sido dividido en tres subgéneros monofiléticos, Aristolochia, Pararistolochia (Hutch. \& Dalz.) O.C. Schmidt y Siphisia (Duch.) O.C. Schmidt (González, 1997, 1999a; Wanke et al., 2006; González et al., 2014), dos de los cuales (Aristolochia y Siphisia) confluyen en Centro América. Aristolochia panamensis Standl., la única especie endémica del país, marca el límite más austral del subgénero Siphisia en el Nuevo Mundo (González et al., 2014). Por su parte, las especies del subgénero Aristolochia presentes en Panamá representan la extraordinaria diversificación morfológica del género en el Neotrópico.

Desde el punto de vista ecológico, las especies de Aristolochia en el Neotrópico desempeñan funciones fundamentales en dos procesos de interacciones plantaanimal. El primero consiste en la utilización de tejido foliar, y ocasionalmente floral, como sitios de oviposición y como fuente exclusiva de alimento por parte de las orugas de papiliónidos de los géneros Battus (Scopoli, 1777) y Parides (Hübner, 1819). Por ejemplo, las tres especies de Aristolochia aquí reportadas para la Isla de Barro Colorado (A. chapmaniana Stand1., A. cordiflora Mutis ex Kunth y $A$. pilosa Kunth), muy probablemente son la única fuente de alimento de las 10 especies de Papilioninae en la isla reportados por Basset et al. (2015). El segundo proceso, menos conocido, tiene que ver con las relaciones de mutualismo entre flores de Aristolochia y dípteros de las familias Drosophilidae, Muscidae, Otitidae y Phoridae y de coleópteros de la familia Staphylinidae. Los dípteros, además de ser polinizadores por lo menos de $A$. grandiflora Sw., A. inflata Kunth y A. maxima Jacq. en Centro América, utilizan el tejido floral en post-antesis o en des- composición como sitios de oviposición o apareamiento (Hilje, 1984; Sakai, 2002).

La revisión taxonómica más completa de las especies de Aristolochia presentes en Panamá fue realizada por Pfeifer (1960), quien reportó 13 especies. El mismo autor (Pfeifer, 1966) redujo a 12 el número de especies y efectuó varias modificaciones taxonómicas con respecto a su trabajo previo (Cuadro 1). Más recientemente, Barringer (1983) propuso una nueva especie restringida a Panamá, A. pfeiferi Barringer.

El objetivo del presente trabajo consiste en la actualización taxonómica, nomenclatural y corológica de las especies panameñas de Aristolochia.

\section{Materiales y Métodos}

Se examinó material perteneciente a los herbarios de A, AAU, BM, C, CAS, COL, CONN, DUKE, F, FIWEBB, FLAS, G, G-DC, GH, GOET, K, MA, MG, MEDEL, MO, MPU, NY, P, PMA, QCA, S, SCZ, SEL, SP, STRI, TEX-LL, U, UC, US y WAG (abreviaturas según Thiers, 2014). Los ejemplares de herbario citados del primer autor (FG) corresponden únicamente a material fotográfico tomado en campo; las copias electrónicas de dicho material fueron depositadas en COL y sus respectivas copias serán depositadas en PMA. Todos los ejemplares tipo examinados han sido marcados con el signo '!'; adicionalmente se examinó la base de datos de las imágenes disponibles en Jstor Global Plants (JSTOR, 2017). En lo posible, se incluyó el código de barras de los duplicados en cada herbario. También se consultó el herbario virtual PMA (2017). Solamente se incluyen los sinónimos que presentan información nueva o actualizada; para sinonimias completas, véase Pfeifer (1966), González (1990, 1994), Rankin Rodríguez y Greuter (1999), González y Lozano (2014) y González et al. (2015). Las categorías infragenéricas seguidas corresponden a las de González $(1990,1991)$ y Ohi-Toma y Murata (2016). La terminología para la descripción de las inflorescencias y flores de Aristolochia sigue a González (1990, 1991, 1994, 1999b) y la usada para describir las formas de los órganos (p. ej. ovado, ovado-angosto, 
Cuadro 1: Comparación entre los tratamientos de Aristolochia para la Flora de Panamá (Pfeifer, 1960) y para Norte y Centro América (Pfeifer, 1966), así como su equivalencia con las especies reconocidas en el presente trabajo. Especies reconocidas en negrita; sinónimos, no en negrita.

\begin{tabular}{|c|c|c|}
\hline Especies reconocidas por Pfeifer (1960) & Especies reconocidas por Pfeifer (1966) & Especies reconocidas en la presente sinopsis \\
\hline A. anguicida Jacq. & No reportada para Panamá & A. anguicida Jacq. \\
\hline A. arborescens $\mathrm{L}$. & excluida & - \\
\hline A. chapmaniana Standl. & A. chapmaniana Standl. & A. chapmaniana Standl. \\
\hline- & A. constricta Griseb. & A. sprucei Mast. \\
\hline A. costaricensis Duch. & A. pilosa Kunth & A. pilosa Kunth \\
\hline- & - & A. cruenta Barringer \\
\hline \multirow[t]{2}{*}{ A. grandiflora $\mathrm{Sw}$. } & A. grandiflora $\mathrm{Sw}$. & A. grandiflora $\mathrm{Sw}$. \\
\hline & "A. grandiflora" & A. cordiflora Mutis ex Kunth \\
\hline A. inflata Kunth & A. inflata Kunth & A. inflata Kunth \\
\hline A. maxima Jacq. & A. maxima Jacq. & A. maxima Jacq. \\
\hline A. nummularifolia Kunth & - & $\begin{array}{l}\text { A. nummularifolia Kunth (Fig. 6), no } \\
\text { presente en Panamá }\end{array}$ \\
\hline A. odoratissima $\mathrm{L}$. & A. odoratissima $\mathrm{L}$. & A. odoratissima $\mathrm{L}$. \\
\hline A. panamensis Standl. & A. panamensis Standl. & A. panamensis Standl. \\
\hline A. sylvicola Standl. & "A. gigantea" & A. cordiflora Mutis ex Kunth \\
\hline- & - & A. ringens Vahl \\
\hline- & - & A. tonduzii O.C.Schmidt \\
\hline- & - & A. trilabiata Glaz. \\
\hline A. trilobata $\mathrm{L}$. & A. trilobata $\mathrm{L}$. & A. trilobata $\mathrm{L}$. \\
\hline A. veraguensis Duch. & A. veraguensis Duch. & A. leuconeura Linden \\
\hline
\end{tabular}

ovado-ancho, etc.) se basó en Stern (1966, Fig. 19). La forma y el tamaño de las semillas son muy similares en las cuatro especies de Aristolochia ser. Thyrsicae, por lo cual éstas solamente se describen en conjunto para la serie. Los caracteres aquí descritos corresponden a los presentes en las especies panameñas del género.

\section{Resultados y Discusión}

Se presenta a continuación la sinopsis taxonómica actualizada de Aristolochia en Panamá.

Aristolochia L., Sp. P1. 2: 960. 1753. TIPO: A. rotunda L. (lectotipo designado por Green (1929)).
Bejucos, lianas o subarbustos aromáticos, frecuentemente con raíces o rizomas engrosados y tallos maduros con una capa suberosa externa, fisurada longitudinalmente; hojas alternas, dísticas, sin estípulas, algunas especies con pseudoestípulas, cada una correspondiente al profilo adaxial, sésil, reducido y envolvente de una rama vegetativa; peciolo a veces con una articulación basal correspondiente a la zona de abscisión foliar; venación foliar palmeada o pinnada; flores axilares, solitarias a lo largo de vástagos de crecimiento indeterminado, o agrupadas en cimas (ripidios) con una o más bracteolas opuestas a las flores, o en racimos caulifloros, extremadamente cortos $(<1 \mathrm{~cm}$ de largo); pedúnculo floral poco diferenciado del ovario, a veces con una articulación basal correspon- 
diente a la zona de abscisión; perianto uni, bi- o trilabiado, formado por tres sépalos petaloides congénitamente fusionados, diferenciado en utrículo (porción sacciforme basal), tubo (porción intermedia, estrecha), y limbo (porción laminar abierta y conspicua); fauces (entrada al tubo del perianto) a veces bordeadas por un anillo; pétalos ausentes; estambres 6 , sésiles, fusionados a los 3 o 6 lóbulos estigmáticos en una estructura llamada ginostemo, ubicada en la parte basal del interior del utrículo; ovario ínfero, 6-carpelar, 6-locular; fruto una cápsula de dehiscencia acrópeta o basípeta; semillas por lo general numerosas por carpelo, aplanadas, aladas o no, a veces con un arilo glutinoso.

El siguiente es el esquema taxonómico seguido en este trabajo y el número de especies de cada taxon infragenérico presentes en Panamá:

1. Aristolochia subg. Siphisia (Duch.) O.C. Schmidt (1 sp.)

2. Aristolochia subg. Aristolochia (15 spp.)

2.1 Aristolochia ser. Hexandrae F. González (11 spp.)

\subsubsection{Aristolochia subser. Hexandrae (8 spp.)}

2.1.1.1. Grupo "Exstipulosae" sensu Hoehne (1942; pseudoestípulas ausentes) (3 spp.)

2.1.1.2. Grupo "Pseudostipulosae" sensu Hoehne (1942; pseudoestípulas presentes) (5 spp.)

2.1.2. Aristolochia subser. Anthocaulicae F. González (3 spp.)

2.2. Aristolochia ser. Thyrsicae F. González (4 spp.)

\section{Clave de identificación de las especies de} Aristolochia presentes en Panamá

1a. Subarbustos; peciolo 1-1.6 cm de largo; lámina foliar elíptica, con base cuneada, envés color grisáceo y venación pinnada; inflorescencias en cimas caulifloras a ramifloras, cortas ( $<4 \mathrm{~cm}$ de largo), con 1-3 flores; limbo del perianto trilobado, el lóbulo medio dirigido hacia abajo y con base buliforme, color amarillo; ginostemo trilobado; cápsula con dehiscencia basípeta; semillas $>2.5 \mathrm{~mm}$ de grosor

..... Aristolochia (subg. Siphisia) panamensis Standl. 1b. Bejucos o lianas; peciolo usualmente $\geq 2 \mathrm{~cm}$ de largo (en A. maxima y A. tonduzii O.C. Schmidt a veces $<2$ $\mathrm{cm}$ ); lámina foliar desde ovado-angosta a reniforme, con base cordiforme, envés color verde claro, rara vez color grisáceo, y venación palmeada; flores solitarias, axilares, o dispuestas en cimas $>5 \mathrm{~cm}$ de largo o en racimos caulifloros o ramifloros, cortos $(<5 \mathrm{~cm}$ de largo), usualmente con $\geq 4$ flores cada uno; limbo del perianto uni- o bilabiado, nunca buliforme, el labio principal dirigido hacia arriba, excepto en $A$. grandiflora, en donde está dirigido hacia abajo y se prolonga en una cauda hasta $1 \mathrm{~m}$ de largo; ginostemo 6-lobado; cápsula con dehiscencia acrópeta (excepcionalmente basípeta en $A$. grandiflora y A. pilosa); semillas $<1 \mathrm{~mm}$ de grosor (desconocidas en A. cruenta Barringer) ... 2 Aristolochia subg. Aristolochia

2a. Peciolo y pedúnculo floral sin zona basal de abscisión; flores axilares, solitarias a lo largo de las ramas foliosas distales, o agrupadas en racimos caulifloros o ramifloros cortos, ebracteoladas o con una bracteola circular perfoliada; cápsulas con septos enteros; semillas ovoides a ovoide-anchas no aladas o con un ala periférica, a veces con un arilo glutinoso en la región calazal (Aristolochia ser. Hexandrae F. González) ... 3

2b. Peciolo y pedúnculo floral con zona basal de abscisión; inflorescencias en cimas (ripidios) con 2-20 flores, cada flor opuesta a una bracteola triangular no perfoliada; cápsulas con septos cancelados; semillas oblongo-anchas, bialadas, el ala abaxial más corta que la adaxial (Aristolochia ser. Thyrsicae F. González) 13

3a. Flores solitarias, axilares a lo largo de ramas foliosas distales con entrenudos $>1 \mathrm{~cm}$ de largo; semillas aladas o no (subser. Hexandrae) 4

3b. Flores densamente dispuestas en racimos caulifloros o ramifloros con entrenudos $<1 \mathrm{~cm}$ de largo, cada flor axilar a una bráctea triangular sésil o subsésil, muy reducida; semillas nunca aladas (subser. Anthocaulicae F. González)

4a. Pedúnculo floral con una bracteola perfoliada, circular, hasta $4 \times 4.5 \mathrm{~cm}$; perianto $>40 \mathrm{~cm}$ (rara vez $<20$ 
$\mathrm{cm}$ ) de largo; anillo presente; limbo $>10 \mathrm{~cm}$ de ancho, con la base dirigida hacia arriba y el ápice prolongado en una cauda filiforme hasta $1.5 \mathrm{~m}$ de largo, dirigido hacia abajo A. grandiflora $\mathrm{Sw}$.

4b. Pedúnculo floral ebracteolado; flores $<20 \mathrm{~cm}$ de largo, anillo ausente, limbo $<8 \mathrm{~cm}$ de ancho, con la base dirigida hacia abajo y el ápice no caudado (caudado en $A$. trilobata L.), dirigido hacia arriba ................ 5

5a. Pseudoestípulas ausentes ....................................... 6

5b. Pseudoestípulas presentes ....................................... 7

6a. Plantas densamente hirsuto-pilosas; peciolo 3-8(10.5) $\mathrm{cm}$ de largo, hirsuto-piloso; lámina ovada a ovado-angosta, $5.6-23.4 \times 3.5-14 \mathrm{~cm}$, por lo menos dos veces más larga que ancha, envés hirsuto-piloso; limbo del perianto unilabiado, superficie interna lisa, papilada o fimbriada; cápsula 4-6.5 cm de largo, hirsuto-pilosa; semillas ovoides, 4.5-5.5 × 3.5$4.5 \mathrm{~mm}$, sin alas ni arilo glutinoso

A. pilosa Kunth

6b. Plantas glabrescentes; peciolo 5-15(-30) cm de largo, glabro; lámina ovado-ancha, 9-20(-29) × 10$20(-28) \mathrm{cm}$, usualmente casi tan larga como ancha, envés esparcidamente pubérulo; limbo del perianto bilabiado, con fimbrias marginales hasta $6 \mathrm{~mm}$ de largo; cápsula $>10 \mathrm{~cm}$ de largo, glabrescente; semillas oblongo-angostas, $3-4 \times 2-3 \mathrm{~mm}$, con un arilo glutinoso alrededor de la rafe ... A. trilabiata Glaziou

7a. Hojas trilobadas; perianto con seis apéndices carnosos, digitiformes, reflexos, hasta $7 \mathrm{~mm}$ de largo, en la base del utrículo y con una cauda hasta $60 \mathrm{~cm}$ de largo en el ápice del limbo A. trilobata $\mathrm{L}$.

7b. Hojas enteras; perianto sin apéndices carnosos en la base del utrículo; ápice del limbo no caudado ........ 8

8a. Hojas reniformes; limbo del perianto bilabiado; cápsulas $>9 \mathrm{~cm}$ de largo y $3 \mathrm{~cm}$ de diámetro; semillas 7-15 $\times 6-10 \mathrm{~mm}$, incluida un ala romboide

A. ringens Vahl

8b. Hojas ovadas a ovado-angostas; limbo del perianto unilabiado; cápsulas hasta $8 \mathrm{~cm}$ de largo y $2.5 \mathrm{~cm}$ de diámetro; semillas triangulares u ovoides, sin alas o con un ala triangular, $<7 \times 6 \mathrm{~mm}$ 9a. Pedúnculo más ovario $4.5-10 \mathrm{~cm}$ de largo; utrículo $15-25(-30) \times 5-8 \mathrm{~mm}$; limbo 4-12 × 2.5-5 cm, superficie interna color rosado y vetas color amarillo; cápsula 4.5-8 cm de largo, de contorno 6-lobado; semillas ovoides, con un arilo glutinoso ... A. odoratissima $\mathrm{L}$.

9b. Pedúnculo más ovario hasta $4.5 \mathrm{~cm}$ de largo; utrículo hasta $18 \times 11 \mathrm{~mm}$; limbo hasta $4 \times 3 \mathrm{~cm}$, superficie interna color amarillo con vetas color morado; cápsula 2.2-4 cm de largo, de contorno circular; semillas triangulares, sin arilo glutinoso 10

10a. Utrículo obovoide, no constricto en su porción media, 2.5-5 mm de diámetro; tubo en ángulo ca. $150^{\circ}$ con el utrículo; limbo ovado-angosto, $0.7-1.3 \mathrm{~cm}$ de ancho, base redondeada, ápice obtuso, no mucronado; cápsula 1.5-2 cm de diámetro, no arqueada; semillas 5.5-6.8 $\times 4.1-6 \mathrm{~mm}$, aladas

\section{A. anguicida Jacq.}

10b. Utrículo oblongo, constricto transversalmente hacia la parte media, 5-11 mm de diámetro; tubo en ángulo ca. $90^{\circ}$ con el utrículo; limbo ovado, $1.5-3.0 \mathrm{~cm}$ de ancho, base cordada, ápice agudo, mucronulado; cápsula $0.5-1.1 \mathrm{~cm}$ de diámetro, levemente arqueadas cuando indehiscente; semillas 2-2.5 × 1-2 mm, no aladas A. inflata Kunth

11a. Hojas neurovariegadas (venas color blanco-amarillentas), envés verde claro, glabrescente a glabro, base profundamente cordado-lobada, no peltada; limbo del perianto oblongo a ovado-angosto; semillas con arilo glutinoso A. leuconeura Linden

11b. Hojas no neurovariegadas, envés color grisáceo, con indumento villoso, base truncada, redondeada o muy levementecordada, ligeramente peltada; limbo del perianto ovado-ancho; semillas sin arilo glutinoso ... 12

12a. Pedúnculo más ovario $5.7-12 \mathrm{~cm}$ de largo; perianto geniculado hacia la parte media del tubo en forma de "U"; utrículo obovoide, lacrimiforme, 50-125 × 20$35 \mathrm{~mm}$; tubo 3-6 $\times 1-2.5 \mathrm{~cm}$, fuertemente arqueado, en ángulo ca. $90^{\circ}$ con el utrículo; limbo muy ovadoancho, 13-30(-35) × 11-23(-30) cm, en ángulo obtuso con el tubo, color rosado a rojo intenso, con venas color amarillo o blanco, fauces color blanco a ama- 
rillentas; ginostemo 6-10 × 5-7 mm; cápsula 10-12 $\times$ $1-1.5 \mathrm{~cm}$ A. cordiflora Mutis ex Kunth

12b. Pedúnculo más ovario $1.6-3.3 \mathrm{~cm}$ de largo; perianto geniculado entre el utrículo y el tubo; utrículo ovoide, $12-23 \times 8-10 \mathrm{~mm}$; tubo $13-26 \times 1-2 \mathrm{~mm}$, recto o muy levemente curvado, en ángulo agudo con el utrículo; limbo ovado-ancho, 30-50.3 × 20.8-40.3 $\mathrm{mm}$, aproximadamente en línea recta con el tubo color amarillo con púrpura en la superficie interna, fauces color púrpura; ginostemo 4-5.2 × 3-4 mm; cápsula ca. $4.5 \times 1 \mathrm{~cm}$.............. A. cruenta Barringer

13a. Lámina foliar oblonga, oblongo-angosta u obovada, base cuneada, truncada o muy levemente cordada (escotadura $<1.5 \mathrm{~cm}$ de profundidad); perianto fuertemente reflexo en especial entre el utrículo y el tubo A. maxima Jacq.

13b. Lámina foliar elíptica, ovada u ovado-angosta, rara vez oblonga o ovado-ancha, base cordada, con escotaduras $>1 \mathrm{~cm}$ de profundidad; perianto levemente curvado a rectilinear.... 14

14a. Haz foliar lisa o glabrescente, no áspera; ripidios hasta $21 \mathrm{~cm}$ de largo, con 10 o más entrenudos; perianto glabrescente o ligeramente pubérulo en la superficie externa, con utrículo obovoide, $8-20 \mathrm{~mm}$ de largo y limbo 25-40(rara vez hasta 50) $\mathrm{mm}$ de largo .... A. sprucei Mast.

14b. Haz foliar áspera; ripidios $<15 \mathrm{~cm}$ de largo, hasta con 5 entrenudos; perianto hirsuto o híspido en la superficie externa, con utrículo elipsoide, 25-50(-70) $\mathrm{mm}$ de largo y limbo 40-125 mm de largo 15

15a. Peciolo 0.6-0.1 cm de largo, híspido; lámina oblonga a angosto-oblonga, hasta $5.5 \mathrm{~cm}$ de ancho, ápice agudo a subobtuso; perianto levemente curvado especialmente entre el tubo y el limbo, superficie externa esparcidamente pubérula; utrículo elipsoidal 25-40(-45) × 7-10 mm; tubo en ángulo ca. $160^{\circ}$ con el utrículo; limbo ovado-angosto (lanceolado), 12-18 mm de ancho, levemente reflexo en el 1/2-1/4 distal, liso en la superficie interna, ápice con un acumen filiforme hasta $1 \mathrm{~cm}$ de largo

A. chapmaniana Standl. 15b. Peciolo 12-50(-60) $\mathrm{mm}$ de largo, hirsuto; lámina oblonga, ovado-angosta o, a veces, elíptica a elíptica-ancha u ovada, hasta $15 \mathrm{~cm}$ de ancho, ápice obtuso a cortamente acuminado; perianto levemente curvado entre el utrículo y el tubo, superficie externa muy densamente hirsuta especialmente a lo largo de las venas; utrículo $28-50(-70) \times 13-18 \mathrm{~mm}$; tubo en ángulo $<160^{\circ}$ con el utrículo; limbo ovado a oblongo-ancho, 2-4 cm de ancho, cuculado, papilado en la superficie interna, ápice agudo, no acuminado

A. tonduzii O.C. Schmidt

1. Aristolochia subg. Siphisia (Duch.) O.C. Schmidt, in Engler \& Prantl, Nat. Pflanzenfam., ed. 2, 16B: 236. 1935. Arbustos, subarbustos o lianas; venación foliar pinnada o palmeada; inflorescencias en cimas; perianto fuertemente geniculado, sin tricomas cónicos en la superficie interna; limbo trilobado, el lóbulo medio dirigido hacia abajo; ginostemo trilobado, cada lóbulo opuesto a un par de anteras; cápsula de dehiscencia basípeta.

1.1. Aristolochia panamensis Standl., J. Wash. Acad. Sci. 15:5. 1925. TIPO: PANAMÁ. "Canal Zone", río Paraíso, above East Paraíso, 7.I.1924, (fr), P. C. Standley 29906 (holotipo: US-US00105864!, isotipo: A-A00099223!). Fig. 1.

Subarbustos hasta $1 \mathrm{~m}$ de alto, a veces con ramas postradas y procumbentes, $30-60 \mathrm{~cm}$ de largo; tallos densamente velutinos; peciolo 1-1.6 cm de largo, densamente velutino; lámina elíptica a ligeramente obovada, 10-25 × 6-14.5 cm, base decurrente a cuneada, usualmente asimétrica, no peltada, ápice agudo a acuminado, haz glabra, envés velutino, glauco, venación pinnada; cimas caulifloras a ramifloras $<4 \mathrm{~cm}$ de largo, con 1 a 3 flores cada una, cada flor opuesta a una bracteola ovado-angosta, $5 \times 1$ $\mathrm{mm}$; pedúnculo más ovario $1.5-3 \mathrm{~cm}$ de largo, densamente velutino; perianto con la superficie externa velutina; utrículo lacrimiforme, $18-20 \times 6-7 \mathrm{~mm}$, no diferenciado del tubo, lóbulos laterales del limbo triangulares, 15-20 $\times$ 18-20 mm, color púrpura, conectados por una ampolla 

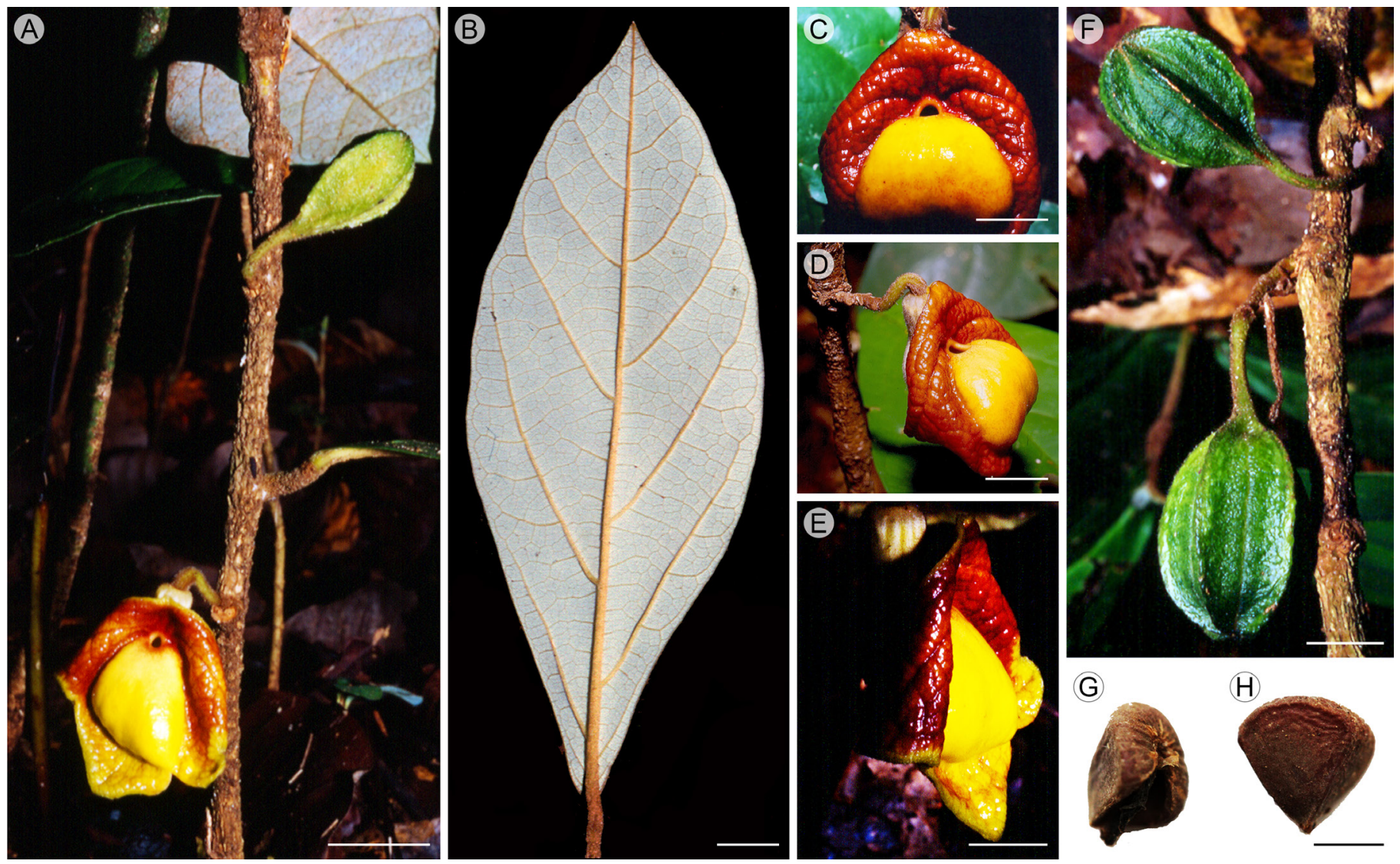

Figura 1: Aristolochia (subgen. Siphisia) panamensis Standl. (Aranda y González 4097, PMA) A. hábito; B. hoja por el envés; C-E. flor, vistas frontal (C), oblicua (D) y lateral (E); F. cápsulas; G-H. semillas, vista adaxial (G) y abaxial (H). Escalas: 2 cm en A; 1 cm en B-F; 2 mm en G, H.

medial color amarillo brillante de ca. $20 \times 15 \mathrm{~mm}$ que limita las fauces de ca. $2 \mathrm{~mm}$ de diámetro, lóbulo medial triangular-ancho, más pequeño, 1-1.5 × 1.4-1.8 cm, color amarillo a vinotinto; ginostemo 3-3.5 × 2-2.5 mm; cápsula cilíndrica, 2-2.5 × 1.4-1.6 $\mathrm{cm}$, velutina; semillas ovoides, hasta $5 \times 4 \mathrm{~mm}, 2.5-3 \mathrm{~mm}$ de grosor, concavoconvexas, sin alas ni arilo glutinoso, rafe prominente.

Distribución: Panamá. Crece en el sotobosque de bosques húmedos primarios o secundarios en buen estado de conservación, por debajo de 200 m de elevación.

Ejemplares examinados: PANAMÁ. Área del Canal, camino a plantación, a $800 \mathrm{~m}$ de la entrada, a ambos lados del río, $9^{\circ} 04^{\prime} \mathrm{N}, 79^{\circ} 39^{\prime} \mathrm{W}, 14 . I X .2002$, (fl, fr), J. Aranda y F. González 4096 (COL, PMA, SCZ,
STRI), 4097 (COL, PMA, SCZ, STRI); Georgia Green Park, 27.VI.1965, (st), R. L. Dressler 2982 (MO, PMA); George W. Green Memorial Park, Madden Road Forest Preserve, 25.X.1970, (fr), R. L. Dressler 3903 (CONN); George W. Green Memorial Park, Madden Road Forest Preserve, 17.VI.1971, (fl), R. L. Dressler 4031 (CONN, PMA); Las Cascadas Plantation, 6.VI.1936, (st), W. R. Lindsay 438 (MO); Las Cascadas Plantation, 30.VII.1937, (fl), W. R. Lindsay 488 (MO); vic. San Félix, eastern Chiriquí, 0-120 m, I.1912 (st), $H$. Pittier 5463 (F, US); San Félix, eastern Chiriquí, 0-120 m, XII.1911, (fl, fr), H. Pittier 5750 (A, F, GH, MO, NY, P, S, US); Las Cascadas Plantation, near Summit, 2.XII.1923, (st), P. C. Standley 25740 (US); Las Cascadas Plantation, near Summit, 4.I.1924, (fr), P. C. Standley 29515 (A, GH, K, MO, NY, US); río Pedro Miguel, 
near East Paraíso, 7.I.1924, (st), P. C. Standley 29950 (US). Chiriquí, E of Gualaca, $500 \mathrm{ft}, 31$.VII.1947, (fl), P. H. Allen 5040 (MO); new road between Pueblo Nuevo and Concepción, ca. 400 m, 30.XI.1979, (fl), $R$. $W$. Read et al. 79215 (US). Colón, vic. of Madden Lake, ca. $9^{\circ} 25^{\prime} \mathrm{N}, 7^{\circ} 35^{\prime} \mathrm{W}, 24$.VIII.1986, (fl, fr), G. McPherson 9989 (PMA). Panamá, La Cascada, Madden Forest, Parque Soberanía, 31.XII.1992, (fr), M. Akers 9 (SCZ, STRI); Panamá, Parque George Green, 18.VI.1972, (fl), L. Carrasquilla 182 (F, PMA). Veraguas, P.N. Coiba, Jicarón, 9.VII.2004, (st), A. Ibáñez 3715 (MO); Los Santos, Guanaquito, about 10 miles north of Tonosi, along río Tonosi, ca. 100-200 m, 17.VII.1970, (fl), J. L. Luteyn y R. Foster 1380 (CONN, F, NY).

2. Aristolochia subgen. Aristolochia. Lianas o bejucos; venación foliar palmeada; flores axilares, solitarias, o dispuestas en cortos racimos o en cimas (ripidios); perianto desde rectilíneo a fuertemente geniculado, con tricomas cónicos en la superficie interna del tubo y, en varias especies, extendidos hasta el limbo; limbo uni- o bilabiado, rara vez trilobado, el labio principal dirigido hacia arriba (excepto en $A$. grandiflora, en donde el ápice del limbo está dirigido hacia abajo); ginostemo 6-lobado, cada lóbulo opuesto a una antera; cápsula de dehiscencia acrópeta.

2.1. Aristolochia ser. Hexandrae. Peciolo y pedúnculo floral sin zona basal de abscisión; flores solitarias, axilares, a lo largo de ramas foliosas distales, o agrupadas en racimos caulifloros o ramifloros cortos, ebracteoladas o, en $A$. grandiflora, con una bracteola circular perfoliada; anillo (reborde alrededor de las fauces) presente en $A$. grandiflora; cápsulas con septos enteros; semillas ovoides a ovoide-anchas, no aladas o con un ala periférica, a veces con un arilo glutinoso en la región calazal.

2.1.1. Aristolochia subser. Hexandrae. Pseudoestípulas presentes o ausentes; flores solitarias, axilares a lo largo de ramas foliosas distales; semillas aladas o no.

\subsubsection{Grupo "Exstipulosae" (pseudoestípulas ausentes)}

2.1.1.1.1. Aristolochia grandiflora Sw., Prodr. Veg. Ind. Occ. 126. 1788. TIPO: JAMAICA. Sin localidad, ni fecha precisas, (fl), P. O. Swartz s.n. (posible holotipo: S!, duplicado BM-BM000040909!). Figs. 2A-E.

$=A$. foetens Lindl., Edwards's Bot. Reg. t. 1824. 1836. Lectotipo, aquí designado: Plancha 1824, Edwards's Bot. Reg. 1836.

$=A$. pichinchensis Pfeifer, Selbyana 2: 29. 1977. TIPO: ECUADOR. Los Ríos, río Palenque Biological Station, km 56 Quevedo - Santo Domingo, 150-220 m, 30.IX.1972, (fl), C. H. Dodson 5215 (holotipo: US-US00105868!, isotipos: MO!, QCA-QCA16151!, SEL-SEL001237!, SELSEL001238!).

$=A$. gorgona M.A. Blanco, Brittonia 54: 31. 2002. TIPO: COSTA RICA. Heredia, Puerto Viejo de Sarapiquí, Estación Biológica La Selva, Quebrada Surá, near the laboratory, $10^{\circ} 26^{\prime} \mathrm{N}, 83^{\circ} 59^{\prime} \mathrm{W}, 50 \mathrm{~m}$, 4.I.2001, (fl), M. Blanco 1752 (holotipo: USJ, isotipos: MO-MO256252!, MOMO256253, NY-NY00579415!, NY-NY00579416!).

A. caudata auct. non Jacq.: L., Syst. Nat. 2: 600. 1767.

A. gigantea auct. non Mart. \& Zucc.: Hooker in Curtis Bot. Mag., t. 4221.1846.

Bejucos de tallos glabrescentes o pubérulos; peciolo 5-15 cm de largo, pubérulo; lámina ovada a ovado-ancha, $6-20(-30) \times 6-16(-21) \mathrm{cm}$, base profundamente cordadolobada, no peltada, escotaduras $1.5-4.3(-7) \mathrm{cm}$ de profundidad, tanto o más profundo que ancho, ápice agudo a acuminado, haz glabrescente, envés color verde claro, pubérulo, venas primarias basales 7(9); pedúnculo más ovario $12-23.5 \mathrm{~cm}$ de largo, a nivel medio con una bracteola perfoliada, circular, $18-40 \times 22-45 \mathrm{~mm}$; perianto $>40 \mathrm{~cm}$ (rara vez $<20 \mathrm{~cm}$ ) de largo, fuertemente curvado, superficie externa tomentosa en flores cerradas, glabrescente en antesis; utrículo obovoide, (60-)100-120(-160) × 20-35 $\mathrm{mm}$, superficie interna con tricomas secretores dispuestos a manera reticulada; tubo fuertemente curvado en la parte media, bullado en la mitad distal, 7-13.5(-18) $\times 1-4$ 

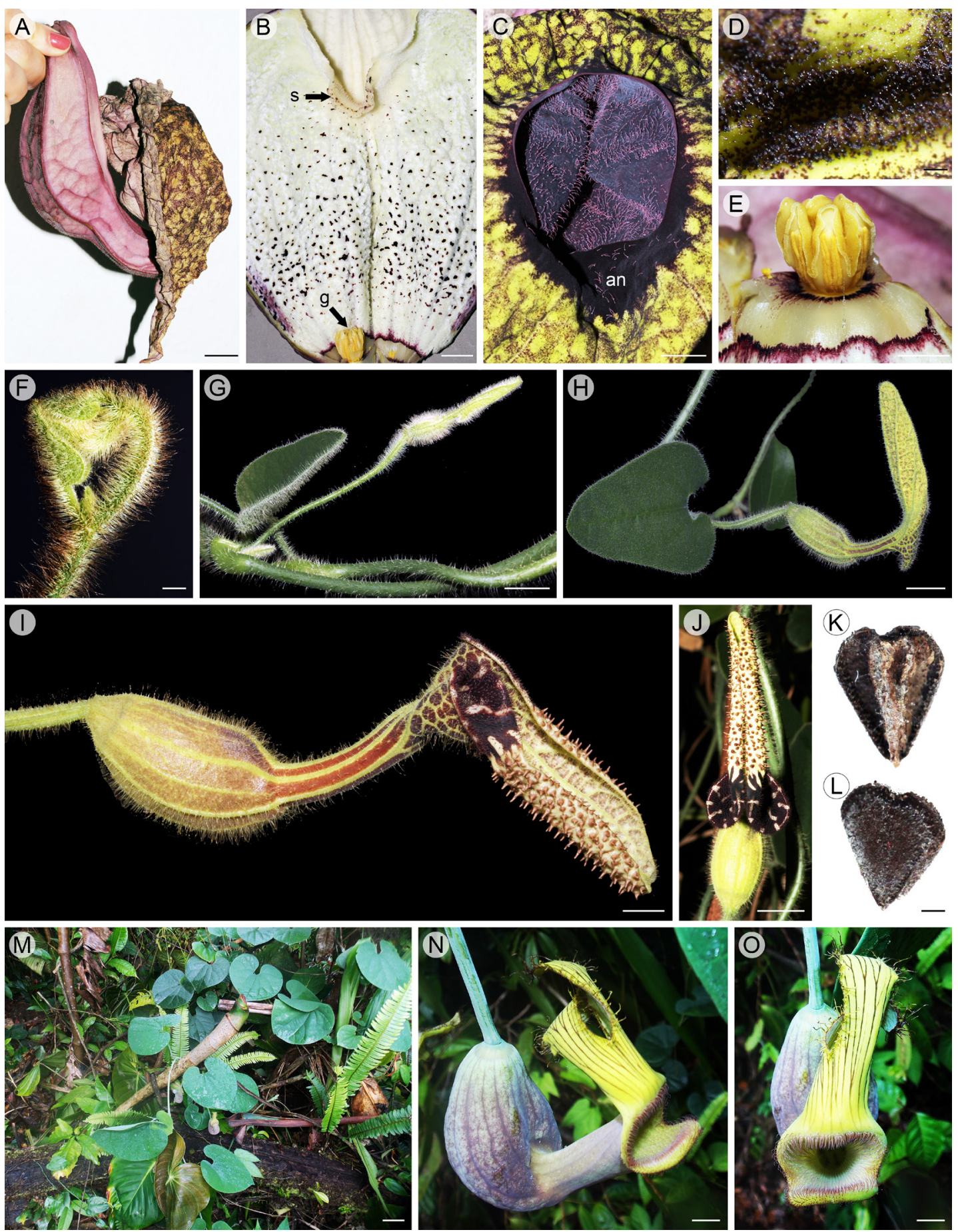

Figura 2: Especies de Aristolochia subser. Hexandrae F. González, grupo "Exstipulosae” presentes en Panamá. A-E. A. grandiflora Sw. A. flor en post-antesis, vista lateral; B. utrículo disecado, note el ginostemo (g) rodeado de una ventana de tejido semitranslúcido en el perianto, y la siringe (s); C. anillo (an) alrededor de las fauces del perianto; D. detalle de papilas en la superficie interna del limbo del perianto; E. ginostemo en fase de liberación de polen; F-L. Aristolochia pilosa Kunth (González 4017, COL) F. ápice de un vástago; G. botón floral antes de resupinación; H. flor resupinada; I, J. flor en antesis, vista lateral (I) y superior (J); K-L. semillas, vista adaxial (K) y abaxial (L); M-O. Aristolochia trilabiata Glaz. (McPherson 21586, MO) M. hábito, N, O. flor en antesis, vista lateral (N) y frontal (O). Escalas: 1 cm en A, B, E, G, H, J, N, O; 5 mm en D, I; 1 $\mathrm{mm}$ en $\mathrm{C}, \mathrm{F}, \mathrm{K}, \mathrm{L} ; 5 \mathrm{~cm}$ en $\mathrm{M}$. 
$\mathrm{cm}$, en ángulo obtuso respecto al utrículo; anillo (reborde entre el tubo y el limbo) $1-1.5 \mathrm{~cm}$ de ancho, reduciendo el diámetro de las fauces a 15-35(-50) $\mathrm{mm}$; limbo unilabiado, obovado-ancho, $(8-) 19-35$ ( superficie interna color rosado, rojo intenso o morado con vetas color blanco-amarillentas, usualmente liso, a veces papilar o con fimbrias en la superficie interna, en ángulo ca. $90^{\circ}$ con el tubo, base cordada, escotaduras hasta $6 \mathrm{~cm}$ de profundidad, dirigida hacia arriba, ápice prolongado en una cauda filiforme (5-)70-150 × 1-2.5 cm, dispuesta en posición inferior; ginostemo 9-16 $\times$ 7-10 mm; cápsula 13-15.5 × 3.2-3.5 cm; semillas ovoide-anchas, 10-14 $\times$ $10-13 \mathrm{~mm}, 0.8-1 \mathrm{~mm}$ de grosor, aplanadas, lisas por ambas caras, no aladas, rafe promínula.

Distribución: México, Centro América (Belice, Honduras, Guatemala, El Salvador, Nicaragua, Costa Rica, Panamá), Jamaica, Colombia y Ecuador. Su presencia en varias islas del Caribe (p. ej. en Cuba, St. Thomas, Guadalupe y Martinica) y en Trinidad puede ser debido a introducción y naturalización. En Panamá crece en bordes de bosque primario y secundario, y de bosques ribereños, por debajo de 1000 m de elevación.

Ejemplares examinados: PANAMÁ. Colón, along the río Guanche, 400 m, 5.VII.1979, (fl), T. Antonio 1230 (MO); walking upstream from bridge over río Guanche, 0-100 m, 19.I.1980, (fl), T. Antonio 3376 (MO); bank of río Cascajal, ca. $1 \mathrm{~km}$ from the sea, 4.IV.1980, (fl), $W$. D’Arcy 13609 (MO); Santa Rita Ridge, 30.XII.1971, (fl), J. D. Dwyer y A. Gentry 9337 (F, MO, NY, STRI); ribera de río Guanche, $9^{\circ} 31^{\prime} \mathrm{N}, 79^{\circ} 40^{\prime} \mathrm{W}$, ca. $100 \mathrm{~m}, 18 . \mathrm{I} .1995$, (fl), C. Galdames y C. Guerra 1931 (FLAS, NY); Santa Rita Ridge east of transisthmian highway, 300-500 m, $20 . I X .1972$ (fl), A. Gentry 6118 (F, MO, NY, WAG); near mouth of río Guanche, 1.X.1972 (fl, fr), A. Gentry 6301 (MO, STRI); Santa Rita Ridge, 22.IX.2002, (fl), $F$. González 4020 (COL, PMA); río Guanche, 3-7 km above bridges, 300-700 ft, 1.X.1978, (fl), B. Hammel et al. 4955 (MO); 1-2 km from the Portobelo Highway up the río Guanche, $9^{\circ} 30^{\prime} \mathrm{N}, 79^{\circ} 40^{\prime} \mathrm{W}, 0-50,17 . I I .1982$ (fl, fr), $S$.
Knapp y R. Schmalzel 3570 (BM, F, MO); Fató (Nombre de Dios), at sea level, VII-VIII.1911, (fl), H. Pittier 4145 (BM, F, GH, MO, NY, US). Darién, trail between Pinogana and Yavisa, ca. 15 m, 17.III.1937, (fl), P. H. Allen 291 (A, MO); vic. Yape, ca. 30 m, 4.X.1938 (fl), P. H. Allen 867 (MO); vic. Pinogana, 20 m, 4.III.1947 (fl), P.H. Allen 4292 (BM, G, MO); near Refugio, 15-21 mi NO of Santafé, ca. 30 m, 16.II.1967 (fl), J. A. Duke 10293 (MO); río Areti, 7.XI.1967, (fl), J. A. Duke y N. H. Nickerson 14923 (MO); río Pirré, between Pirré and El Real, 30.XII.1972, (fl), A. Gentry et al. 7093 (MO, TEX-LL). Panamá, a 10 $\mathrm{m}$ del río Chagres y a $150 \mathrm{~m}$ del puente, 15.II.1976, (fl), E. Ballesteros 35 (MO); Serranía de Majé, trail along río Ipetí, nr. confluence with río Ambroino, $100 \mathrm{~m}, 8^{\circ} 57^{\prime} \mathrm{N}$, $79^{\circ} 32^{\prime}$ W, s.f. (fl), H. W. Churchill et al. 4476 (MO, PMA). San Blas, río Cangandí, pueblo Cangandí, 0-20 m, 9²7'N, $7^{\circ} 07^{\prime} \mathrm{W}$, s.f. (fl), H. Herrera 362 (MO); Cangandí, 30 m, 924'N, 79²4'W, 27.III.1986, (fl), G. de Nevers et al. 7614 (MO, PMA). Sin localidad precisa, "Panamá”, 1962 (fl, fr), J. A. Ducke 6142 (F, MO, NY).

Comentarios taxonómicos y nomenclaturales: Lindley (1836) basó la descripción de Aristolochia foetens en una colección procedente de las "West Indies, whence it has been obtained by Mrs. Marryat, in whose stove at Wimbledon it flowered in June last". Debido a que no existe ejemplar de herbario correspondiente a dicha colección, se designa la Plancha 1824 en Edwards's Bot. Reg. (1836) como lectotipo de la especie ya que esta ilustración, probablemente a partir de una planta en cultivo, reproduce de manera precisa los caracteres diagnósticos del protólogo.

Blanco (2002) describió Aristolochia gorgona como especie nueva, basada en colecciones procedentes de Costa Rica y de Panamá. Recientemente, Barringer (2014) propuso reducir este binomio a la sinonimia de $A$. grandiflora, aunque no aportó evidencia para dicha decisión. Enseguida presentamos detalladamente los criterios que justifican dicha subordinación. Los caracteres diagnósticos señalados en la descripción original de A. gorgo$n a$ son el mayor tamaño floral, el limbo del cáliz plicado, 
la presencia de fimbrias y la menor longitud de la cauda (“Aristolochiae grandiflorae Sw. affinis, sed floribus majoribus, limbus calyce plicatus frontalis atque infra tubus calyce, projecturae parvulae vermiformis interius obtecta, cauda minore.”; Blanco, 2002). Tanto el tamaño total del perianto como de la cauda se encuentran dentro de la variación que ocurre en $A$. grandiflora; por ejemplo, el espécimen tipo de $A$. grandiflora, procedente de Jamaica, posee una cauda de similar tamaño (ca. $9 \mathrm{~cm}$ de largo) que la de $A$. gorgona. Variaciones importantes en el tamaño floral de $A$. grandiflora, incluso dentro de la misma población y el mismo individuo, ocurren en respuesta a condiciones ambientales determinadas (Hilje, 1984). En cuanto al limbo plegado ("plicatus"), este rasgo temporal se presenta en los estados iniciales de antesis floral en todas las especies de Aristolochia, ya que el limbo cambia drásticamente de una estructura cerrada mediante interdigitación de sus márgenes, durante la cual el limbo del cáliz siempre es plicado, a una fase totalmente expandida en la que es frecuente que el limbo llegue a ser retrorso en post-antesis (Figs. 2A-C, 4A-D). En cuanto a la presencia de fimbrias ("tentacles" sensu Blanco, 2002) como carácter diagnóstico de $A$. gorgona, el estudio de numerosos ejemplares de herbario en $A$. grandiflora, incluidos el material tipo y los tres ejemplares panameños asignados a A. gorgona (Gentry et al. 7093, Churchill et al. 4476 y Ducke 6142) demuestra una variación en la superficie interna del limbo, desde lisa, papilada (Fig. 2D) o fimbriada, variación conocida en otras especies (p. ej. A. pilosa, Figs. 2I, J; González, 1990).

Las semillas en Aristolochia proporcionan varias características importantes en la taxonomía infragenérica y la identificación de las especies (Huber, 1985; González y Rudall, 2003). En su trabajo, Blanco (2002) se refiere a las semillas de $A$. gorgona como engrosadas, a diferencia de las semillas planas (o aplanadas) de $A$. grandiflora descritas por González (1990), y le atribuye esta última condición al aborto de las semillas. El uso del término "semillas planas" se refiere al contorno en sección transversal de ésta y otras especies (p. ej. A. odoratissima Figs. $3 \mathrm{G}, \mathrm{H}$; A. ringens Fig. 3S; A. trilobata, Figs. $3 \mathrm{~V}$, W), a diferencia del contorno cóncavo-convexo observado en semillas de muchas otras especies (p. ej. A. cordiflora Figs. 4G, H; A. pilosa Figs. 2K, L; A. panamensis, Figs. 1G, H; véase González, 1999a; González y Rudall, 2003). Al mismo tiempo, Blanco (2002) describió las semillas de A. gorgona como obovoides; las semillas en Aristolochia son ovoides, ya que provienen de óvulos anátropos, y la parte más ancha de la semilla propiamente dicha corresponde a la base y la inserción de la rafe (González, 1999a; González y Rudall, 2003). Por lo tanto, no existen diferencias en las semillas de $A$. gorgona y de $A$. grandiflora.

En la descripción de Aristolochia gorgona, Blanco (2002) invocó alopatría entre $A$. grandiflora, restringida en Costa Rica a la vertiente Pacífica y $A$. gorgona, de la vertiente Caribeña. No obstante, los numerosos registros que demarcan una amplia distribución de $A$. grandiflora (México, las dos vertientes de Centro América, Las Antillas, Colombia y Ecuador) muestran que todos los ejemplares asignados a A. gorgona de Costa Rica y Panamá resultan totalmente anidados en la distribución geográfica de $A$. grandiflora .

Blanco (2005) describió la formación, bajo condiciones de invernadero, de un híbrido espontáneo entre $A$. grandiflora y A. gorgona. No obstante, los dos supuestos individuos "parentales" no fueron sometidos a rigurosos experimentos de polinización cruzada, lo cual invalida cualquier posible explicación causal del fenotipo obtenido en la $F_{1}$ y deja sin evidencia el supuesto de que "[1]a pronta aparición de un híbrido en condiciones de cultivo entre estas especies indica que ambas utilizan el mismo tipo de dípteros polinizadores, y que el aislamiento geográfico es el factor responsable de mantener su integridad genética" (Blanco, 2005).

En la discusión acerca de la sinonimia de Aristolochia grandiflora, Blanco (2002) malinterpretó el estatus de los binomios A. caudata y A. gigantea, originalmente descritos por Jacquin (1760) y Martius y Zuccarini (1824), respectivamente. La revisión cuidadosa de las descripciones de estos binomios por Linneo (1767) y Hooker (1846) no dejan duda que estos últimos autores se referían a $A$. grandiflora. Estos nombres fueron tratados 
por Pfeifer (1966) y González (1990) como identificaciones incorrectas ("misidentifications") que, de acuerdo al Código Internacional de Nomenclatura Botánica actual (McNeill et al., 2012) en su recomendación 50D, no deben ser incluidas en la sinonimia sino agregadas luego de ésta "50D.1 Misidentifications should not be included in synonymies but added after them. A misapplied name should be indicated by the words "auct. non" followed by the name(s) of the original author(s) and the bibliographic reference of the misidentification". En atención a esta recomendación, se incluyen en el presente trabajo estos dos nombres luego de la sinonimia de la especie.

\subsection{Aristolochia pilosa Kunth, Nov. Gen. Sp. Pl. 2:} 146, t. 113. 1817. TIPO: ECUADOR. "Crescit in ripa inundata fluvii Daule prope Guayaquil (Regno Quitensi.)" s.f. (fl), A. von Humboldt y A. Bonpland s.n. (holotipo: P-P00669996!). Figs. 2F-L.

= A. pannosa Mast., J. Linn. Soc., Bot. 14: 493. 1875. TIPO: PERÚ. "Prope Yurimaguas locis graminosis ad flumen Huallaga”, V.1855, (fl), R. Spruce 3901 (holotipo: K-K000323618!).

= A. costaricensis Duch. var. zamorensis Hieron., Bot. Jahrb. Syst. 20: 5. 1895. TIPO: ECUADOR. Zamora, "Crescit ad margines silvarum prope Zamora Andium orientalium, Prov. Loja, 1000-1200 m”, IX.1888, (fl), F. C. Lehmann 4827 (lectotipo, aquí designado: K-K000323620!, isolectotipos: F-F578328!, GHGH00098241!, K-K000323619!, NY-NY285546!).

=A. pilosa HBK. var. ligulifera Mast. ex Donnell-Smith, Bot. Gaz. 33: 256. 1902. TIPO: GUATEMALA. Alta Verapaz, Cubilquitz, 350 m, III.1901, (fl), H. von Tuerckheim 7768 (lectotipo designado por González (1990): US-US00026827!, isolectotipos: A-A00035996!, GHGH00035997!, NY!, US-US00026828!).

= A. amazonica Ule, Verh. Bot. Vereins Prov. Brandenburg 47: 122. 1905. TIPO: PERÚ. Loreto, Cainarachi, IX.1902 (fl, fr), E. Ule 6406 (lectotipo designado por González (1990): L!, isolectotipos: B (destruido, foto en F-F0BN004896), F-F0048808F!, G-G00237204!, MG!).
= A. ferruginea Brandegee, Univ. Calif. Publ. Bot. 6: 51. 1914. TIPO: MÉXICO. Chiapas, sin localidad, ni fecha precisas, 1913, (fl, fr), C. A. Purpus 6931 (holotipo: UC-UC173035!, isotipos: BM-BM000617134!, F-F0048794F!, GH-GH00035993!, MO!, NYNY00312362!, US-US00026830!).

$=$ A. ernestulei Hoehne, Mem. Inst. Oswaldo Cruz 20: 86, pl. 83. 1927. TIPO: BOLIVIA. Río Acre, Cobija, seringal San Francisco, XII.1911, (fl), E. Ule 9341 (holotipo: MG!, isotipos: F-F0048813F!, F0BN004911!, G-G00237203!). = A. eggersii Hoehne, Arquiv. Bot. Estado São Paulo, n.s., form. maior, 1: 135. 1944. TIPO: ECUADOR. Manabí, El Recreo, 10.II.1897, (fl), H. F. A. Eggers 15082 (holotipo: US-US00105830!, isotipos: BM-BM000040596!, FF0048812F!, K-K000323621!).

$=$ A. haughtiana Hoehne, Arquiv. Bot. Estado São Paulo, n.s., form. maior, 2: 99, t. 37. 1947. TIPO: COLOMBIA. Antioquia, río Chado, $65 \mathrm{~km}$ south of Turbo, 60 m, 7.V.1945, (fl, fr), O. Haught 4648 (holotipo: USUS00026829!, isotipos: COL!, SP-SP000404!).

= A. medellinensis Hoehne, Arquiv. Bot. Estado São Paulo, n.s., form. maior, 2: 99, t. 36. 1947. TIPO: COLOMBIA. Antioquia, Medellín, “en el río”, X.1935, (fl), Hno. Daniel 866 (holotipo: US-US00323952!, isotipos: COLCOL00001151!, MEDEL-MEDEL000035!).

$=A$. claveriana L. Uribe, Caldasia 7: 33. 1955. TIPO: COLOMBIA. Cundinamarca, Santandercito, Hacienda San Claver, 1700 m, XI.1952, (fl, fr), L. Uribe-Uribe 2504 (holotipo: COL-COL000001145!, isotipos: NYNY00285543!, NY-NY00285544!, U-U0004619!).

Bejucos densamente hirsuto-pilosos; peciolo 3-8($10.5) \mathrm{cm}$ de largo, hirsuto-piloso; lámina ovada a ovadoangosta, 5.6-23.4 × 3.5-14 cm, por lo menos dos veces más larga que ancha, base cordado-lobada, escotaduras 0.5-3.8 cm de profundidad, ápice agudo a obtuso, envés densamente piloso, venas primarias basales 5 ; pedúnculo más ovario 3.5-10 cm de largo; perianto ligeramente curvado, con la superficie externa densamente hirsuto-pilosa; utrículo elipsoide u obovoide, 15-35 × 5-10 mm; tubo 1.5$3.5 \times 0.1-0.5 \mathrm{~cm}$, en ángulo ca. $150^{\circ}$ con el utrículo; limbo 
unilabiado, ovado a elíptico, $2-5 \times 0.7-2 \mathrm{~cm}$, en ángulo ca. $90-120^{\circ}$ con el tubo, superficie interna efimbriada, papilada o fimbriada, color morado con vetas color verdeamarillentas en la superficie interna, a veces con fimbrias en la cara interior, ápice agudo a obtuso, mucronulado o brevemente emarginado; ginostemo 4.5-7 × 2-3.5 mm; cápsula 4-6.5 × 1.6-2 cm, hirsuto-pilosa; semillas ovoides, 4.5-5.5 × 3.5-4.5 mm, concavo-convexas, sin alas ni arilo glutinoso, rafe prominente.

Distribución: México, Centro América (Guatemala, Belice, Costa Rica, Panamá), Colombia, Venezuela, Ecuador, Perú y Bolivia. En Panamá crece en bordes de bosques secundarios y matorrales, por debajo de $1000 \mathrm{~m}$ de elevación.

Ejemplares examinados: PANAMÁ. Área del Canal, around Gamboa, 40-80 m, 1911, (fl), H. Pittier 4431 (GH). Bocas del Toro, vicinity of Chiriquí lagoon, 18.X.1940, (st), H. von Wedel $1228(\mathrm{GH})$; vicinity of Chiriquí lagoon, 21.X.1940 (fl), H. von Wedel $1267(\mathrm{GH})$. Darién, vicinity of Yape, ca. 30 m, 4.X.1938, (fl), P. H. Allen $864(\mathrm{GH})$; trail from El Real to cerro Pirre, 7.III.1972, (st), A. Gentry 4582 (BM); río Cocalito, 19.II.1982 (fl), $C$. Whitefoord y A. Eddy 259 (BM); Mamey, 8.III.1982 (fl), C. Whitefoord y A. Eddy 424 (BM). Panamá, monumento Natural Barro Colorado, ca. Snider Molino, 2.II.2000, (fl), R. Aizprúa B-1717 (PMA, SCZ, STRI); Parque Nacional Chagres, road from cerro Jefe to Altos de Pacora, 900 m, 9 9 $13^{\prime} \mathrm{N}, 7^{\circ} 22^{\prime} \mathrm{E}, 25 . \mathrm{I} .2005$ (fl), M. Blanco 2872 (FLAS); Barro Colorado Island, 16.V.1968, (fl), T. Croat 5599 (SCZ); Barro Colorado Island, lab clearing near Donato trail, 8.I.1969, (fl), T. Croat 7005 (SCZ); Barro Colorado Island, 23.III.1970, (fl), T. Croat 9011 (SCZ, STRI); Barro Colorado Island, Canal Zone, 3.XI.1967, (fl), R. L. Dressler 3139 (PMA); Barro Colorado Island, 1.VII.1960, (fl), J. E. Ebinger 241 (SCZ); Barro Colorado Island, 20.IX.2002, (fl), F. González 4017 (COL, PMA); around Alhajuela, Chagres valley, 30-100 m, 11.I.1911, (st), H. Pittier $2326(\mathrm{GH})$; Barro Colorado Island, 17.X.1931, (st), O. Shattuck 164 (GH). San Blas, env. of
Puerto Obdaldia, $8^{\circ} 40^{\prime} \mathrm{N}, 7^{\circ} 25^{\prime} \mathrm{W}, 0 \mathrm{~m}, 16 . \mathrm{IV} .1982$, (fl), S. Knapp y J. Mallet 4625 (PMA).

Comentarios taxonómicos y nomenclaturales: Existen cinco pliegos correspondientes a la colección original de Aristolochia costaricensis var. zamorensis (Lehmann 4827), ninguno de los cuales fue designado como holotipo. Se procede a designar, como lectotipo, el pliego K-K000323620, ya que es el más completo, y presenta más datos manuscritos en la etiqueta original.

2.1.1.1.3. Aristolochia trilabiata Glaziou, Bull. Soc. Bot. France 58 (Mém. 3f): 578. 1911. TIPO: BRASIL. "Espirito Santo", IX-X (sin año), (fl), A. F. M. Glaziou 10033 (lectotipo, aquí designado: P-P01657954!, isolectotipos: C-C10022101!, K!). Figs. 2M-O.

$=A$. didyma $\mathrm{S}$. Moore, J. Bot. 53: 7. 1915. TIPO: BRASIL. "Environs of Pará; Utinga and Souza", M. Moss s.n. (sintipos: BM-BM000040886!, BM-BM000040887!, MG!, S!, US-US00105827!, lectotipo, aquí designado: BM-BM000040886), syn. nov.

= A. rodriguesii Hoehne (as rodriguessi), Mem. Inst. Oswaldo Cruz 20: 140. 1927. TIPO: BOLIVIA. Cobija, I.1912, (fl), E. Ule 9338 (lectotipo designado por Ahumada (2010): MG-MG14186!).

Bejucos de tallos glabrescentes; peciolo 5-15(-30) cm de largo, glabro; lámina ovado-ancha, 9-20(-29) $\times 10$ $20(-28) \mathrm{cm}$, con frecuencia casi tan larga como ancha, base cordado-lobada, escotaduras 1-5(-6) cm de profundidad, no peltada, ápice agudo, envés glaucescente a color grisáceo, esparcidamente pubérulo especialmente sobre las venas, venas primarias basales 5(7); pedúnculo mas ovario 11-21 cm de largo, glabro; perianto fuertemente curvado entre el utrículo y el tubo, con la superficie externa glabra; utrículo obovoide, 46-75 $\times 22-40 \mathrm{~mm}$; tubo cilíndrico, (2.5-)3.5-8 cm de largo, 0.7-2.1 cm de diámetro, en ángulo ca. $30^{\circ}$ con el utrículo; limbo bilabiado, en ángulo ca. $180^{\circ}$ con el tubo, superficie interna color amarillo-verdoso con vetas color morado, lóbulo superior 
3.5-6.8 × 4-6.5 cm, bilobado, cada lóbulo hasta $3.3 \mathrm{~cm} \mathrm{de}$ ancho, ápice emarginado hasta por ca. 1/3 o 1/2 de la longitud total del limbo, con un mucrón de 2-5 mm de largo, margen con fimbrias hasta $6 \mathrm{~mm}$ de largo, lóbulo inferior ovado-ancho, $1-2 \times 1.4-2.5 \mathrm{~cm}$; ginostemo 10-15 × 6-10 $\mathrm{mm}$; cápsula 10-25 × 1.5-2.5 cm; semillas oblongo-angostas, 3-4 × 2-3 mm, concavo-convexas, no aladas, con un arilo glutinoso alrededor de la rafe prominente.

Distribución: Panamá, Colombia, Ecuador, Venezuela, Perú, Guyanas, Brasil y Bolivia.

Ejemplares examinados: PANAMÁ. Panamá, Colón, near Petaquilla, $8^{\circ} 51^{\prime} \mathrm{N}, 80^{\circ} 40^{\prime} \mathrm{W}$, 14.IX.2007, (fl), G. McPherson y J. Meerman 19520 (MO, PMA), 19663 (MO, PMA); Colón, Donoso, 92 m, 849'43"N, 80³7'25"W, 13.IX.2012, (fl), G. McPherson 21586 (MO).

Comentarios taxonómicos y nomenclaturales: Aristolochia trilabiata fue publicada postumamente en una corta descripción del Bulletin de la Societé Botanique de France (Glaziou, 1911), como parte de la descripción de las especies recolectadas por el naturalista y paisajista francés A.F.M. Glaziou (1828-1906) en Brasil central entre 1861 y 1895. Aunque este binomio no ha sido empleado desde su publicación original, el ejemplar Glaziou 10033 recolectado en Espíritu Santo (Brasil) fue especificamente mencionado en la descripción original. Existen dos pliegos de este ejemplar que muestran los caracteres diagnósticos típicos de la especie, principalmente la presencia de un limbo floral diferenciado en dos lóbulos laterales, fimbriados, dispuestos en posición superior, y un tercer lóbulo considerablemente más corto en posición inferior. No obstante, ninguno de estos duplicados fue designado como holotipo, por lo cual se designa como lectotipo aquí el depositado en P-P01657954, debido a que muestra en mayor detalle dichos caracteres diagnósticos, la información original manuscrita en la etiqueta es más completa, y muestra la afiliación directa del colector con el herbario P. No hay duda que se trata de la misma especie descrita cuatro años después como $A$. didy$m a$. Por lo tanto, este último binomio se reduce aquí a la si- nonimia de $A$. trilabiata, teniendo en cuenta que el nombre es válido de acuerdo al Art. 36.1 del vigente Código Internacional de Nomenclatura Botánica (McNeill et al., 2012).

La descripción de Aristolochia didyma está basada en varias colecciones de M. Moss, desafortunadamente no enumeradas, efectuadas en 1912 y 1913. De éstas, el autor no designó ninguna como holotipo, por lo cual se hace necesario designar un lectotipo. Existen cinco pliegos correspondientes a Moss s.n., depositados en BM, MG, S y US. Dos de estos pliegos poseen etiquetas con el sitio de colección correspondiente al estado de Pará, Brasil, y el único que posee la localidad específica mencionada en la descripción original "Utinga", BM-BM000040887, desafortunadamente no posee flores. El segundo pliego depositado en BM-BM000040886, es aquí designado como lectotipo, teniendo en cuenta la anotación original manuscrita efectuada por el colector del mismo, y las dos flores que muestran los caracteres diagnósticos de la especie.

\subsubsection{Grupo "Pseudostipulosae"" (pseudoestí- pulas presentes)}

2.1.1.2.1. Aristolochia anguicida Jacq., Enum. Syst. P1. 30. 1760. Lectotipo designado por González (1990): Jacquin, Select. Stirp. Amer. Hist. 112, t. 220. 1780 (iconografia). Figs. 3A-D.

=A. pavoniana Duch., Ann. Sci. Nat. Bot. sér. 4, 2: 55 . 1854. TIPO: MÉXICO. Sin localidad ni fecha precisas, “ex herb. Pavón” (fl), J. M. Mociño y M. Sessé s.n. (ex herb. Pavón) (holotipo: FI-WEBB, FI011391!, isotipo: G-G00237086!).

= A. loriflora Mast., Bot. Jahrb. Syst. 8: 220. 1887. TIPO: GUATEMALA. Chiquimula, 400 m, 9.VII.1882, (fl), F. C. Lehmann 1702 (lectotipo designado por González (1990): US-US00323945!, isolectotipos: BM, FF0048795F!, G-G00237087!, K-K000323505!).

Bejucos pubérulos; peciolo 2-6.5 cm de largo; lámina entera, ovada, a veces ovado-angosta u ovado-ancha, 4.5-15(-17.2) × 3.5-9(-11.6) cm, base cordada, en 
ocasiones truncada, no peltada, escotaduras hasta $36 \mathrm{~mm}$ de profundidad, ápice agudo a obtuso, haz glabrescente, envés pubérulo en las venas y en las aréolas, venas primarias basales 5; pedúnculo más ovario hasta $4.5 \mathrm{~cm}$ de largo; perianto levemente arqueado entre cada una de sus partes, superficie externa glabrescente; utrículo obovoide, 6-13 $\times 2.5-5 \mathrm{~mm}$; tubo $1-2 \times 0.1-0.25 \mathrm{~cm}$, en ángulo ca. $150^{\circ}$ con el utrículo; limbo unilabiado, muy ovado-angosto, $1.5-3.6 \times 0.7-1.3 \mathrm{~cm}$, en ángulo ca. $150^{\circ}$ con el tubo, superficie interna color amarillo con vetas color morado, base redondeada, color amarillo, ápice obtuso; ginostemo 3-4 × 1.8-2.2 mm; cápsulas 2.2-3.8 × 1.5-2 cm; semillas ovoides, 5.5-6.8 $\times$ 4.1-6 mm, planas, con una ala periférica que forma cerca de la mitad de la superficie total de la semilla; semilla propiamente dicha anchamente ovoide, ca. $3 \times 2-4 \mathrm{~mm}$, rafe promínula.

Distribución: México, Centro América (Guatemala, Honduras, El Salvador, Nicaragua, Costa Rica, Panamá), Antillas, norte de Colombia, Venezuela y Guyana Francesa. En Panamá crece al borde de bosques y matorrales costeros en los litorales Caribe y Pacífico, por debajo de 150 m de elevación.

Ejemplares examinados: PANAMÁ. Área del Canal, Transect 1, TTC, 9.V.1973, (fr), A. Gentry 7385 (MO); prov. Los Santos, Managre beach $5 \mathrm{mi}$ SE Chitre, 22.I.1966, (fr), E. L. Tyson et al. 3016 (PMA). Chiriquí, $10 \mathrm{mi}$ E of Nata at río Grande, 4.I.1969, (fr), E. L. Tyson y H. Loftin 5119 A (MO). Coclé, $10 \mathrm{mi}$ E Nata at Río Grande, 4.I.1969, (fr), E. L. Tyson 5217 (MO, SCZ, STRI). Los Santos, Playa de la Concepción, 24.XII.1966, (fl, fr), D. Burch et al. 1261 (GH, K, MO, NY, UC, US); Monagre beach, 29.VII.1963, (fr), J. D. Dwyer 5045 (MO).

Comentarios taxonómicos y nomenclaturales: Jacquin $(1760,1763)$ no refirió ningún ejemplar original como base para la descripción de A. anguicida. González (1990) designó como lectotipo la lámina 220 que acompaña a la descripción que por extenso hace el mismo autor (Jacquin, 1780).
2.1.1.2.2. Aristolochia inflata Kunth, Nov. Gen. Sp. P1. 2: 145, t. 111. 1817. TIPO: COLOMBIA. Tolima, Honda, s.f. (fl, fr), A. Bonpland s.n. (lectotipo, aquí designado: P-P00669994!, isolectotipos: P-P00152023!, P-P00152024!).

= A. gibbosa Duch., Ann. Sci. Nat. Bot. sér. 4, 2: 53 . 1854. TIPO: MÉXICO. Sin datos precisos de localidad o fecha, 1837 (fl, fr), K. T. Hartweg s.n. (lectotipo, aquí designado: G-G00237093!, isolectotipos: K-K000323511!, P-P00623664!).

Bejucos de tallos glabros; peciolo 2-5.6 cm de largo; lámina entera, ovado-oblonga, 4-10.5 × 3.5-6.5 cm, base cordada, no peltada, escotaduras $0.5-2 \mathrm{~cm}$ de profundidad, ápice subagudo, haz glabra, envés glabrescente a esparcidamente pubérulo, venas primarias basales 5; pedúnculo más ovario $2-3 \mathrm{~cm}$ de largo; perianto geniculado entre el utrículo y el tubo, superficie externa glabra; utrículo oblongo, constricto transversalmente hacia la parte media, 7-18 $\times 5-11 \mathrm{~mm}$; tubo ligeramente arqueado, 0.5$1 \times 0.1-0.4 \mathrm{~cm}$, en ángulo ca. $90^{\circ}$ con el utrículo; limbo unilabiado, ovado, 1.8-3.5 $\times 1.5-3 \mathrm{~cm}$, superficie interna color amarillo brillante con venas color vináceo, en ángulo obtuso con el tubo, base cordada, ápice agudo, mucronulado, ginostemo 3-4.5 × 2-4 mm; cápsula 3-4 × 0.5-1.1 $\mathrm{cm}$, ligeramente arqueada cuando indehiscente; semillas ovoides, 2-2.5 × 1-2 mm, levemente concavo-convexas, no aladas, rafe ovoide-angosta, promínula y ensanchada lateralmente en prolongaciones membranáceas más cortas que la semilla propiamente dicha.

Distribución: México, Centro América (Guatemala, El Salvador, Honduras, Panamá) y Colombia. En Panamá crece en matorrales y bosques secundarios secos, por debajo de $400 \mathrm{~m}$ de elevación.

Ejemplares examinados: PANAMÁ. Coclé, La Pintada, 28.XI.1972, (fl), I. de León 3 (F, MO, PMA); between Aguadulce and The Chico river, ca. 20 m, 7-9. XII.1911, (fl, fr), H. Pittier 5008 (BM, GH, NY, US); Pe- 

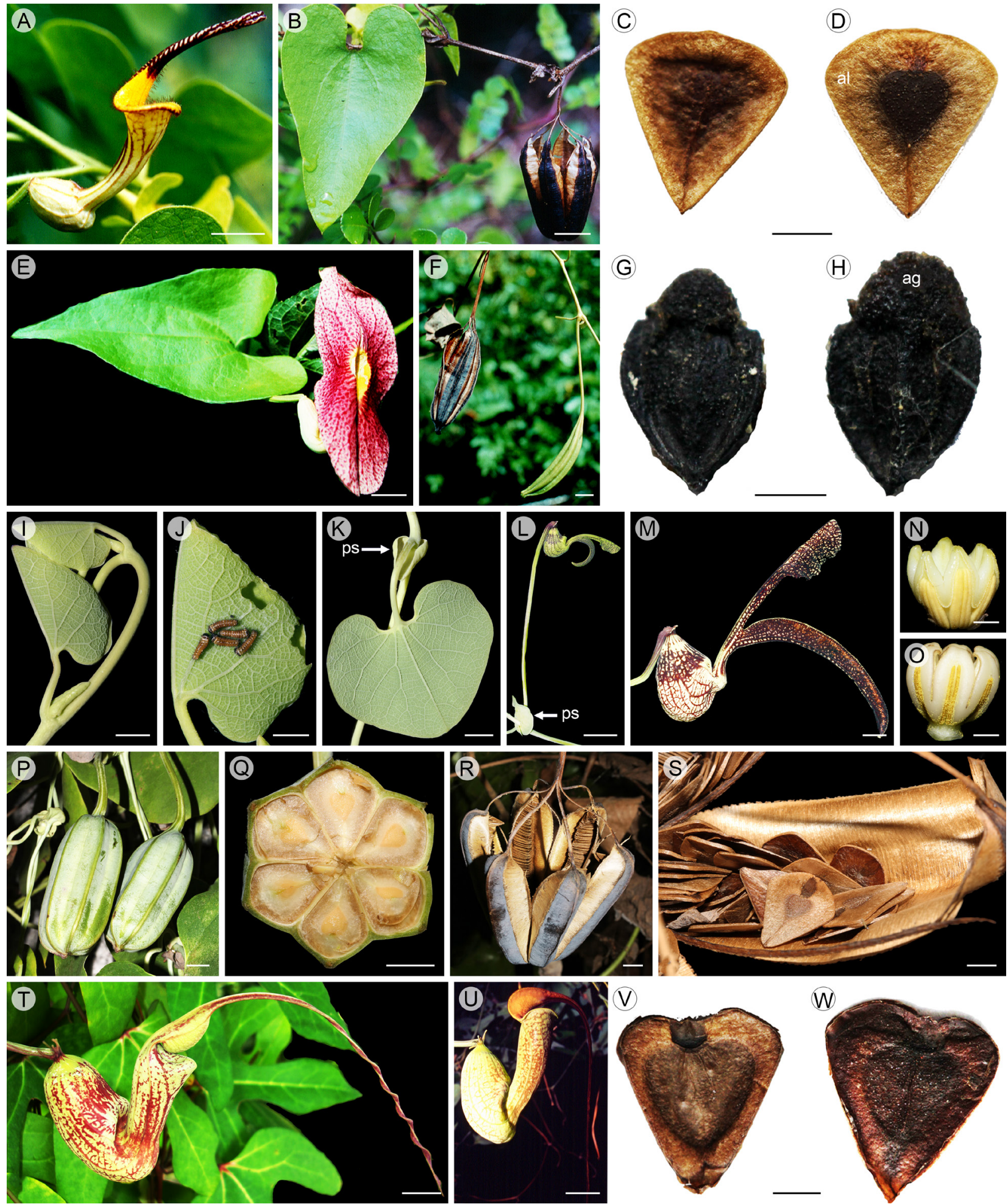

Figura 3: Especies de Aristolochia subser. Hexandrae F. González, grupo "Pseudostipulosae" presentes en Panamá. A-D. Aristolochia anguicida Jacq. A. flor, vista lateral; B. hoja y cápsula; C, D. semillas con ala periférica completa (al), vistas adaxial (C) y abaxial (D); E-H. Aristolochia odoratissima L., E. hoja y flor; F. cápsulas; G-H. semillas con arilo glutinoso (ag), vistas adaxial (G) y abaxial (H); I-S. Aristolochia ringens Vahl. I. ápice de un vástago; J. hojas y orugas de Battus sp. en segundo estadío; K. hoja y pseudoestípula (ps); L. pseudoestípula (ps) y botón floral antes de resupinar; M. flor, vista lateral; N-O. ginostemo en fases sucesivas de receptividad de estigmas (N) y liberación de polen (O); P. cápsulas predehiscentes; Q. sección transversal de cápsula pre-dehiscente; R. cápsula dehiscente; S. semillas. T-W. Aristolochia trilobata L. (González 4016, COL) T. hojas y flor; U. flor, vista lateral; V-W. semillas, vistas adaxial (V) y abaxial (W). Escalas: $1 \mathrm{~cm}$ en A, B, E, F, K-M, P-R, T, U; 2 mm en C, D, I, N, O, V, W; 1 mm en G, H, J; 5 mm en S. 
nonomé and vic. 500-1000 ft, 23.II.-22.III.1908, (fr), $R$. S. Williams 204 (NY, US). Herrera, vic. of Chitré, ca. 20 m, 26.XI.1938, (fl, fr), P. H. Allen 1101 (GH, MO, NY, US); hills between Las Minas and Pesé, 9000-12000 ft, 25.XII.1960, (fl, fr), D. Burch et al. 1327 (GH, MO, US). Panamá, vic. Pacora, ca. 35 m, 5.XI.1939, (fl, fr), P. H. Allen 2032 (F, GH, MO, NY, US); US Army Tropical Test Center, Fort Clayton, Albrook tower, 5.I.1966, (fl), K. E. Blum 2051 (STRI); Canal Zone, Farfán beach, from Thatcher hwy to Palo Seco, 27.XII.1966, (fl, fr), D. Burch et al. 1405 (F, GH, K, MO, NY, P, PMA, UC, US); Parque Natural Metropolitano, 12.XII.1995, (fl, fr), C. Galdames y F. Oedegaard 2392 (PMA, SCZ, STRI), 2398 (PMA, SCZ, STRI); about Panama, s.f. (fl), S. Hayes s.n. (BM); camino del Corozal, XI.1921, (fl, fr), Hno. Heriberto 247 (F, G, GH, NY, US); Parque Natural Metropolitano, área de La Grúa, 22.XII.2004, (fr), S. Paton s.n. (US); Prov. Sabanas N of Panamá City, (fl), Bro. Paul 587 (US); Agricultural Experiment Station at Matías Hernández, 24.XI.1914, (fl, fr), H. Pittier 6872 (BM, F, GH, MO, NY, US); “prope urban Panama”, s.f. (fl, fr), W. Purdie 288 (K); near Punta Paitilla, 7.XII.1923, (fl), P. C. Standley 26246 (US); along the Corozal road, near Panamá, 13.XII.1923, (fr), P. C. Standley 26770 (US); Taboga Island, XII.1923, (fl, fr), P. C. Standley 27029 (US); vic. of Juan Francgo Race Track, 21.XII.1923, (fr), P. C. Standley 27296 (US); Taboga Island, XII.1923, (fl), P. C. Standley 27963 (US); Tumba Muerto road, near Panama, 6.I.1924, (fl), P. C. Standley 29796 (F). Sin localidad ni datos precisos, "Isthmus", 1859-1862, (fr), S. Hayes 146 (GH); I.1860, (fl, fr), S. Hayes 294 (NY); 12.XII.1859, (fl, fr), S. Hayes 781 (NY); entre Acapulco y Panamá, $L$. Neé s.n. (MA); “iter Sagos”, s.f. (fl, fr), L. Neé s.n., (MA); "Panamá", (fl, fr), B. C. Seemann 288 (BM).

Comentarios taxonómicos y nomenclaturales: Existen tres pliegos de Aristolochia inflata asignados a colecciones de A. Bonpland efectuadas en Honda, además de un pliego recolectado por Humbold, sin localidad, y depositado en B (B-W-17064-010). Desafortunadamente en la descripción original, Kunth (1817) no mencionó los ejemplares pero sí la localidad ("Crescit in ripa fluminis Magdalenae prope Honda, 120 hex"). Por lo tanto, se designa aquí como lectotipo de la especie al ejemplar P-P00669994, verificado por Kunth, ya que es el más completo y presenta los caracteres de flores y frutos diagnósticos de la especie.

Aristolochia gibbosa fue descrita por Duchartre (1854) con base en un ejemplar recolectado por Hartweg (sin número) en México en 1837, del cual existen tres pliegos, en G, P y K. Una colección posterior efectuada en Guatemala ("San Antonio Retaleu", 1840 (fl, fr) Hartweg 566, BM-BM000617131, F-F0BN004915, FI-WEBB， K-K000323510， K-K000323511， NYNY00285530) fue tentativamente asignada como lectotipo y anotado como tal en el duplicado depositado en K-K000323511, aunque no fue publicada como tal. Por lo tanto, se designa aquí como lectotipo de este binomio al duplicado depositado en G-G00237093, debido a que los datos de su etiqueta ("Mexique, 1837") coinciden con los anotados en la descripción original.

\subsection{Aristolochia odoratissima L., Sp. Pl. ed. 2:} 1362. 1763. TIPO: JAMAICA. Lámina de Sloane, Voy. Jamaica 1: t. 104, f. 1, 1707 (lectotipo designado por Howard (1988)). Figs. 3E-H.

Bejucos glabrescentes; peciolo 3-6.5 cm de largo, glabrescente; lámina entera, ovada, a veces ovado-angosta, 4-17 $\times 3-13 \mathrm{~cm}$, con frecuencia sagitada a hastada, base cordada, escotaduras 1-3.7 cm de profundidad, ápice agudo a cortamente acuminado, a veces obtuso o emarginado, haz glabrescente, envés pubérulo, venas primarias basales (3)5; pedúnculo más ovario de $4.5-10 \mathrm{~cm}$ de largo; perianto fuertemente curvado especialmente entre el utrículo y el tubo, superficie externa glabra; utrículo obovoide, 15-25($30) \times 5-8 \mathrm{~mm}$, base no apendiculada; tubo 3-5 $\times$ 0.15-0.45 $\mathrm{cm}$, en ángulo ca. $90^{\circ}$ con el utrículo; limbo unilabiado, ovado, 4-12 × 2.5-5 cm, en ángulo ca. $90^{\circ}$ con el tubo, superficie interna color rosado a rojo con vetas y fauces color amarillo, ápice agudo, mucronado, no apendiculado; ginostemo 3.5-4.5 × 2-3.5 mm; cápsula 4.5-8 × 1-1.5 cm, 
de contorno 6-lobado, levemente arqueada, rostrada; semillas ovoide-anchas, 3-3.5 × 2-2.5 mm, planas, hasta 0.8 $\mathrm{mm}$ de grosor, no aladas, con arilo glutinoso.

Distribución: Sur de Estados Unidos de América (Florida), México, Centro América (Guatemala, Belice, Honduras, Nicaragua, Costa Rica, Panamá), Antillas, Colombia, Venezuela, Ecuador, Perú, Bolivia, Paraguay, Brasil y noreste de Argentina. En Panamá crece en bordes de bosques secundarios y matorrales secos, por debajo de 500 m de elevación.

Ejemplares examinados: PANAMÁ. Bocas del Toro, Changuinola Valley, 15.III.1924, (fr), V. C. Dunlap 556 (F, US); Water Valley, 14. IX.1940, (fl), H. von Wedel 791 (GH, MO); vic. Chiriquí Lagoon, 15.X.1940, (fl), $H$. von Wedel 1200 (GH, MO, US); Water Valley, 9.XI.1940, (fl), H. von Wedel 1556 (GH, MO, US); vic. Chiriquí Lagoon, Old Bank Island, 10.II.1941, (fr), H. von Wedel 2046 (GH, MO, US); Bastimentos, Mariano Creek, 4.XI.1941, (fl), H. von Wedel 2903 (GH, NY, US). Panamá, Tocumen, 12.III.1966, (fl, fr), J. D. Dwyer et al. 7243 (MO).

2.1.1.2.4. Aristolochia ringens Vahl, Symb. Bot. 3: 99. 1794. TIPO: JAMAICA. Sin localidad, ni fecha precisas, (fl), J. von Rohr s.n. (lectotipo, aquí designado: BM-BM000040913!, isolectotipos: C-C10006620, C-C10006621, C-C10006624, PH-PH00042345). Figs. 3I-S.

$\equiv$ A. grandiflora Vahl, Symb. Bot. 2: 94, t. 47. 1791, non Swartz (1788).

= A. turbacensis Kunth, Nov. Gen. Sp. Pl. 2: 149. 1817. TIPO: COLOMBIA. Bolívar, "Carthagena, crescit prope Turbaco", IV.1801, (fr), A. Bonpland 1486 (holotipo: P-P00152031!).

Lianas con tallos glabros; peciolo 4.5-11.4(-13) cm de largo, glabro; lámina entera, reniforme, 5-16(-17.5) $\times$ 6-18(-20.5) cm, glabra, base cordada, escotaduras 1.5-5.0 $\mathrm{cm}$ de profundidad, ápice obtuso, redondeado, levemente emarginado o mucronulado, venas primarias basales 5(7); pedúnculo más ovario $7.5-17.5 \mathrm{~cm}$ de largo; perianto geniculado entre el utrículo y el tubo, superficie externa glabra; utrículo obovoide, $50-70 \times 25-40 \mathrm{~mm}$; tubo 3-4 × 0.4-1 cm, en ángulo ca. $90^{\circ}$ con el utrículo; limbo bilabiado, labios en ángulo ca. $180^{\circ}$ respecto al tubo, superficie interna color vináceo a púrpura con vetas y venación color amarillo, labio superior espatulado, 6-9 cm de largo, 1-1.5 cm de ancho proximal, $2.5-4.5 \mathrm{~cm}$ de ancho distal, patente, ápice obtuso a redondeado, sin mucrón, margen liso, labio inferior ovado-angosto, 10-15 cm de largo, 2-3 cm de ancho, levemente curvado, ápice agudo; ginostemo 8-11 × 5-8 mm; cápsula 6-11 × 2.5-3.5 cm; semillas 7-15 $\times 6-10 \mathrm{~mm}$, planas, con un ala romboide periférica amplia; semilla propiamente dicha ovoide, 3-4 × 2-4 mm, rafe linear, promínula.

Distribución: Centro América (Guatemala, Costa Rica, Panamá), Jamaica, Cuba, República Dominicana, Guadalupe, Puerto Rico, Colombia y Venezuela. En Panamá crece en bordes de bosques secundarios, por debajo de 500 m de elevación.

Ejemplares examinados: PANAMÁ. Coclé, Distrito Penonomé, road from Churuquita Grande to Caimito, $380 \mathrm{~m}, 8^{\circ} 40^{\prime} \mathrm{N}, 80^{\circ} 12^{\prime} \mathrm{E}, 22 . \mathrm{I} .2005$, (fr), M. Blanco y D. Penneys 2862 (FLAS, PMA); Penonomé and vicinity, 501000 ft, 23.II-22.III.1908, (fr), R. S. Williams 527 (NY). Panamá, carretera a Cerro Azul, 19.XII.1998, (fl), C. Galdames y R. Gabrielli 4369 (PMA, SCZ, STRI); Pacora, 11.II.1978, (fl), C. Martínez 59 (F, PMA).

Comentarios taxonómicos y nomenclaturales: El binomio Aristolochia grandiflora Vahl es un homónimo posterior de A. grandiflora Sw., reemplazado como tal por $A$. ringens Vahl (1794), y a su vez descrito con base en una colección de J. von Rohr (sin número) procedente de Jamaica. Debido a que existen varios pliegos correspondientes a esta colección, se designa aquí como lectotipo el pliego depositado en BM-BM000040913, debido a que es el más completo y posee la etiqueta manuscrita "Jamaica, J. von Rohr" que indica su procedencia y colector. 
2.1.1.2.5. Aristolochia trilobata L., Sp. Pl. 2: 960. 1753. TIPO: REPÚBLICA DOMINICANA. Cordillera Septentrional, prov. Puerto Plata, Puerto Plata, Playa Colón, 21.III.1930, E. L. Ekman H14492 (neotipo designado por Rankin Rodríguez y Greuter (1999): US-US00811364!, isoneotipos: GH!, S, R-9090!). Figs. 3T-W.

Lianas de tallos glabros; peciolo 1.5-6 cm de largo; lámina profundamente trilobada, rara vez subentera, 5-14 × 6-17 cm, lóbulos hendidos hasta la mitad de la lámina o casi siempre más profundos, oblongos, elípticos u ovadoangostos, cada uno 1.4-4 cm de ancho; base de la lámina truncada o ligeramente cordada, escotaduras hasta $1.2 \mathrm{~cm}$ de profundidad, ápice de los lóbulos agudo u obtuso, haz glabra, envés pubérulo, venas pimarias basales 5, el lóbulo medio con una sola vena de primer orden, los laterales con dos venas de primer orden cada uno; pedúnculo más ovario hasta $7 \mathrm{~cm}$ de largo; perianto geniculado entre el utrículo y el tubo, superficie externa glabra; utrículo elipsoide, 25-55 × 15-20 mm, con la base prolongada en seis apéndices carnosos, digitiformes, reflexos, cada uno hasta $7 \mathrm{~mm}$ de largo; tubo $2.5-5.5 \times 0.6-1.4 \mathrm{~cm}$, en ángulo recto o agudo con el utrículo; limbo unilobado, ovado-ancho, $1.5-2.2$ ( sin la cauda) $\times 1.8-4(-4.5) \mathrm{cm}$, en ángulo ca. $180^{\circ}$ con el tubo, superficie interna color amarillo-verdoso con vetas color morado, base ligeramente cordada, ápice prolongado en una cauda filiforme de 15-60 × 0.3-0.6 cm; ginostemo 8-10 × 5-7 mm; cápsula 6-8.5 × 2-2.5 cm; semillas ovoide-anchas, aplanadas, 7.5-8.5 × 7-8 mm, incluída un ala periférica que ocupa aproximadamente la mitad de la superficie de la semilla, rafe linear, promínula.

Distribución: Estados Unidos de América (Florida), México, Centro América (Belice, Honduras, Nicaragua, Costa Rica, Panamá), Antillas, Colombia, Venezuela, Guyana, Surinam, Guyana Francesa, Brasil, Paraguay, Argentina y probablemente Bolivia. En Panamá crece en bosques costeros, por debajo de $100 \mathrm{~m}$ de elevación.

Ejemplares examinados: PANAMÁ. Área del canal, Fort Clayton, 13.VIII.1967, (st), R. J. Garner 5 (SCZ,
STRI); cerca al antiguo Fort Clayton, 19. IX.2002, (fl), F. González 4016 (COL, PMA). Bocas del Toro, vic. Chiriquí Lagoon, 29.X.1940, (fl), H. von Wedel 1404 (GH, MO, US); Water Valley, 3.XII.1940, (fl), H. von Wedel 1812 (GH, MO, US). Colón, trail above río Indios, along Caribbean Sea, 5 m, 7.VII.1976, (fl), G. A. Sullivan 128 (MO). Panamá, Chagres, 4.III.1850, (fl), A. Fendler 440 (K, MO); Chagres, II.1850, (fl), A. Fendler 445 (MO).

Comentarios taxonómicos y nomenclaturales: Barringer (2014) incluyó dentro de la sinonimia de Aristolochia trilobata a A. surinamensis Willd. probablemente debido a la similitud superficial de la morfología foliar, ya que las dos especies presentan hojas trilobadas. Los siguientes caracteres diferenciales tanto vegetativos como florales confirman que se trata de dos especies diferentes: Aristolochia surinamensis carece de pseudoestípulas; 3 de las 5 venas primarias de la lámina foliar irrigan el lóbulo central y las 2 restantes irrigan a cada uno de los lóbulos laterales; el utrículo, 1-1.7 × 0.7-0.9 $\mathrm{cm}$, carece de proyecciones digitiformes retrorsas en $\mathrm{su}$ base; el tubo, $3.5 \times 0.2-0.8 \mathrm{~cm}$, forma un ángulo de 100 $140^{\circ}$ con el utrículo; el limbo, $1.8-3.4 \times 1.4-3 \mathrm{~cm}$, posee un ápice obtuso a redondeado, a veces emarginado, nunca caudado, y fimbrias en la margen y la superficie interna; y las semillas, 4-5 × 2-3 mm, son concavo-convexas, con rafe prominente, y carecen de alas. En comparación, A. trilobata posee pseudoestípulas; solamente una de las 5 venas primarias irriga el lóbulo central de la lámina foliar; el utrículo $25-55 \times 15-20 \mathrm{~mm}$, posee seis apéndices carnosos, digitiformes, reflexos en la base, cada uno hasta $7 \mathrm{~mm}$ de largo; el tubo, 2.5-5.5 $\times 0.6-1.4 \mathrm{~cm}$, se dispone en ángulo recto o agudo con el utrículo; el limbo, 1.5-2.2 (sin la cauda) $\times 1.8-4(-4.5) \mathrm{cm}$, posee un ápice prolongado en una cauda filiforme 15-50 × 0.3-0.6 $\mathrm{cm}$; y las semillas, 7.5-8.5 $\times 7-8 \mathrm{~mm}$, son planas, aladas, y con rafe linear.

2.1.2. Aristolochia subser. Anthocaulicae. Pseudoestípulas ausentes; flores densamente dispuestas en cortos racimos caulifloros o ramifloros $<8 \mathrm{~cm}$ de largo, con 
entrenudos cortos (hasta $1 \mathrm{~cm}$ de largo), cada flor axilar a una bráctea triangular sésil o subsésil, muy reducida, $<8 \times 5 \mathrm{~mm}$.

\subsubsection{Aristolochia cordiflora Mutis ex Kunth, Nov.} Gen. Sp. Pl. 2: 149. 1817. TIPO: COLOMBIA. (Lectotipo, aquí designado: lámina XXIV de la Iconografía de la Flora de la Real Expedición Botánica al Nuevo Reino de Granada, isolectotipos: láminas XXVI y XXVIII de la misma iconografía (González y LozanoContreras (2014)). Figs. 4A-H.

$=$ A. glaucescens Kunth, Nov. Gen. Sp. Pl. 2: 147, t. 115. 1817. TIPO: COLOMBIA. "Crescit in Regno Novogranatensis juxta St. Anam, 300 hex.”, VI.1801, (fl), A. Bonpland s.n. (lectotipo (segundo paso), aquí designado: P-P00669998!, isolectotipos: P-P00152010!, P-P00152011!).

= A. clypeata Linden \& André, Ill. Hort. 17: 223, t. 40. 1870. TIPO: COLOMBIA. Crescit in sylvis Caucæ (Nova-Granada), G. Wallis s.n., perdido (lectotipo, aquí designado: Linden y André, 1870).

= A. sylvicola Standl., J. Wash. Acad. Sci. 15: 5.1925. TIPO: PANAMÁ. Área del canal, hills north of Frijoles, 19.XII.1923, (fr), P. C. Standley 27469 (holotipo: USUS00323949!, isotipo: US-US00323948!).

Lianas de tallos glabros; peciolo 5-14.2 cm de largo, glabro; lámina ovada a muy ovado-ancha, (5-)9-22.5 $\times(5-) 8.5-19.5 \mathrm{~cm}$, base truncada a levemente cordada, ligeramente peltada, escotaduras hasta $1.8 \mathrm{~cm}$ de profundidad, ápice agudo a cortamente acuminado, haz glabra, envés color verde claro a grisáceo, usualmente villoso, venas primarias basales 5(7); racimos hasta $7 \mathrm{~cm}$ largo; pedúnculo más ovario $5.7-12 \mathrm{~cm}$ de largo; perianto fuertemente curvado, con la superficie externa glabrescente; utrículo obovoide, lacrimiforme, 50-125 × 20-35 mm; tubo 3-6 × 1-2.5 cm, en ángulo ca. 90 con el utrículo; limbo unilabiado, ovado-ancho, 13-30(-35) × 11-23(-30) $\mathrm{cm}$, en ángulo obtuso con el tubo, superficie interna color rosado a rojo intenso, con venas color blanco, fauces co- lor blanco a amarillentas, ápice obtuso, mucronulado; ginostemo 6-10 × 5-7 mm; cápsula 10-12 × 1-1.5 cm; semillas ovoide-angostas, 5-6 × 3-4 mm, concavo-convexas, no aladas, rafe prominente.

Distribución: Costa Rica, Panamá, Colombia y Ecuador. En Panamá crece en bosques pluviales primarios o secundarios, por debajo de 1500 m de elevación.

Ejemplares examinados: PANAMÁ. Área del canal, about 900 m mark, M. Wheeler trail, 20-23.XII.1931, (fl), R. H. Wetmore y E. C. Abbe 01 (F, GH, MO, SCZ), $01 A(\mathrm{~F}, \mathrm{GH}, \mathrm{MO}, \mathrm{SCZ})$. Darién, vic. Paya, río Paya, trail between Paya and Palo de las Letras, 10.VI.1959, (fl), W. L. Stern et al. 204 (GH). Panamá, Lake Gatun, Barro Colorado Island, 4.25 m, 5.XI.1980, (fl), J. Ackerman 1380 (SEL); Summit Garden, 25.IX.1970, (fl), T. Croat 12308 (MO, SCZ, STRI); Changuinola Valley, 18.IX.1923, (fl), V. C. Dunlap 247 (US); Barro Colorado Island, Miller 13.8, 20.X.1978, (fl), R. B. Foster 2916 (SCZ); Barro Colorado Nature Monument, Gigante Peninsula, 19.XII.1988, (fl), N. C. Garwood y J. Cavelier 2771 A (SCZ); Summit Botanic Garden, 21.IX.2002, (fl), F. González 4019A (COL, PMA); along El Llano Carti Tupile road, 12 mil above Pan - Am hwy 200-500 m, 2627.III.1973, (fl, fr), R. L. Liesner 1116 (F, MO, US); Barro Colorado Island, N corner of main laboratory building, 11.XI.1981, (fl), R. S. Schmalzel 052 (MO); NE corner of main lab building, 29.XI.1982, (fl), R. S. Schmalzel 1241 (MO); BCI, 23.XII.1931, (fl), O. E. Shattuck 640 (F, MO); BCI, Gatun Lake, 120 m, 18-24.XI.1925, (st), P. C. Standley 40866 (US).

Comentarios taxonómicos y nomenclaturales: El nombre Aristolochia cordiflora está basado en la serie de láminas elaboradas durante la Expedición Botánica al Reino de Granada, además de dos ejemplares depositados en el Real Jardín Botánico de Madrid (MA-MUT 771, MA660596, MA-MUT 4192, MA660597) y del ejemplar recolectado por A. Bonpland (Colombia. Bolívar: "Crescit prope Mompox ad ripas fluminis Magdalenae", Bon- 

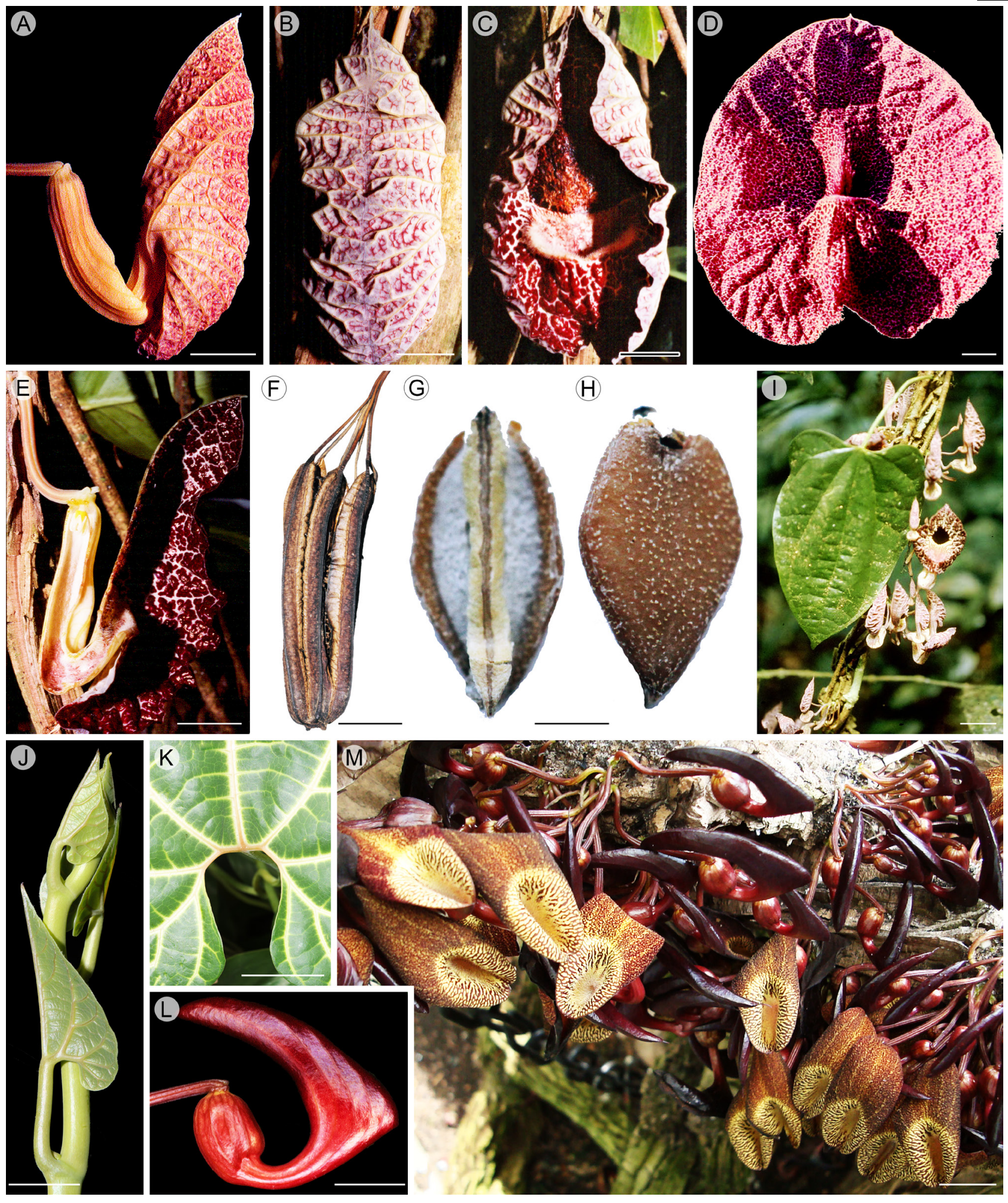

20
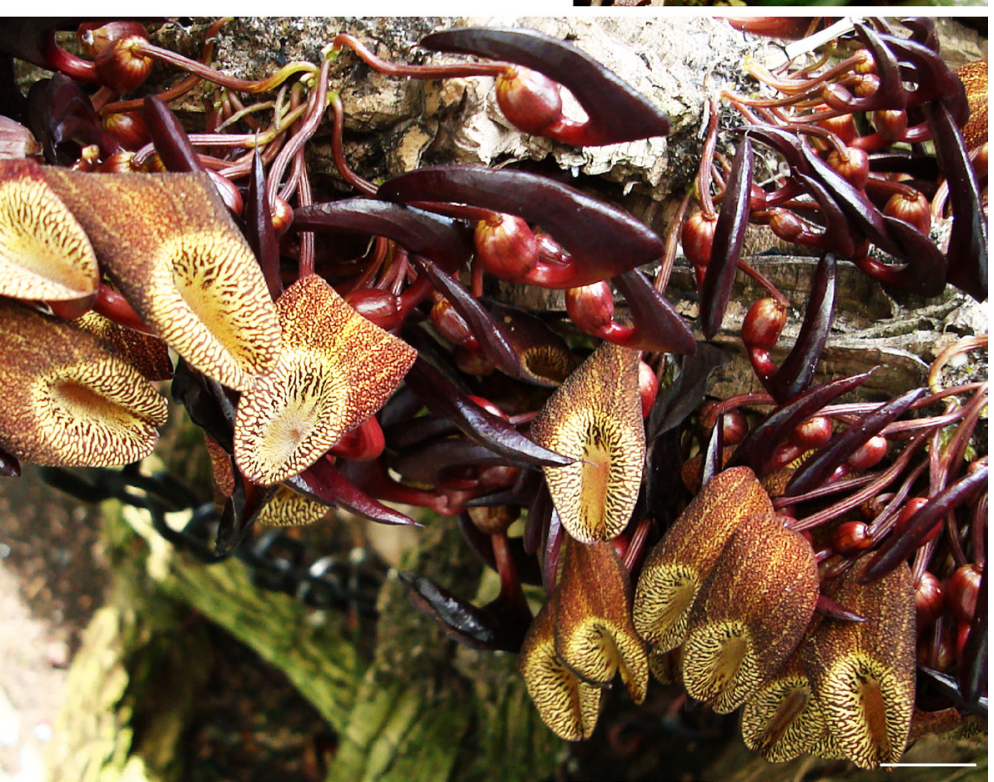

Figura 4: Especies de Aristolochia subser. Anthocaulicae F. González presentes en Panamá. A-H. Aristolochia cordiflora Mutis ex Kunth (González $4019 \mathrm{~A}, \mathrm{COL}$ ). A, B. flor en preantesis, vista lateral (A) y frontal (B); C-D. estados sucesivos de antesis, vista frontal; E. corte sagital del botón floral; F. cápsula; G-H. semilla, vistas adaxial (G) y abaxial (H); I. Aristolochia cruenta Barringer, fotografía del ejemplar tipo (Hammel 10242, DUKE); J-M. A. leuconeura Linden (González 4019, COL) J. ápice del vástago; K. detalle de la base foliar, vista adaxial; L. flor en preantesis, vista lateral; M. racimos caulifloros. Escalas: $1 \mathrm{~cm}$ en A, K, L, M; 2 cm en B-F, I; 1 mm en G, H; 4 mm en J. 
pland s.n., P) y que sirvió de base para la validación del nombre por parte de Kunth (1817). De este material original, designamos aquí como lectotipo la lámina XXIV que ilustra en más detalle los caracteres florales diagnósticos de la especie. Se designa el pliego P-P00669998, como lectotipo de Aristolochia glaucescens, debido a que es el único de los tres ejemplares originales que presenta un botón floral completo, además de los caracteres foliares. Linden y André (1870) basaron su descripción de Aristolochia clypeata en un ejemplar recolectado en la antigua provincia del Cauca, "Nueva Granada" por el naturalista alemán Gustav Wallis (1830-1878). Debido a que no fue posible encontrar un ejemplar de herbario que corresponda a esta colección, se designa como lectotipo la ilustración que acompaña a la descripción original de este binomio (Linden y André, 1870). La especie de la Isla de Barro Colorado referida por Croat (1978) como Aristolochia gigantea Mart. \& Zucc. corresponde a A. cordiflora. González (1990) concluyó que la similitud en la forma y el tamaño de la flor en estas dos especies es una adquisición independiente y que las dos especies presentan numerosas diferencias en los órganos vegetativos, las inflorescencias, los frutos y las semillas, además de la distribución disyunta, ya que $A$. cordiflora es propia de Panamá, Colombia y Ecuador, en tanto que $A$. gigantea se distribuye en el centro, oriente y suroriente de Brasil.

\subsubsection{Aristolochia cruenta Barringer, Brittonia 35:}

171. 1983. TIPO: COSTA RICA. Heredia, Finca La Selva, OTS Field Station on the río Puerto Viejo just $\mathrm{E}$ of its junction with the río Sarapiquí, $100 \mathrm{~m}$, Harshorn Trail, 850 m E, 20.X.1980, (fl, fr), B. E. Hammel 10242 (holotipo: DUKE-DUKE100000924!). Fig. 4I.

Lianas de tallos glabrescentes; peciolo 3.3-6.5 cm de largo, glabrescente; lámina ovado-ancha, 9-14 × 7-12 cm, base truncada a levemente cordada, ligeramente peltada, escotaduras hasta $0.8 \mathrm{~cm}$ de profundidad, ápice acuminado, haz glabra, envés color verde claro a grisáceo, glabro, venas primarias basales 5; racimos hasta $3 \mathrm{~cm}$ de largo; pedúnculo más ovario $1.6-3.3 \mathrm{~cm}$ de largo; perianto geni- culado entre el utrículo y el tubo, con la superficie externa glabrescente; utrículo ovoide, 12-23 × 8-10 mm; tubo 1.3$2.6 \times 0.1-0.2 \mathrm{~cm}$, recto o muy levemente curvado en ángulo agudo con el utrículo; limbo unilabiado, ovado-ancho, $3-5.3 \times 2.8-4.3 \mathrm{~cm}$, en ángulo ca. $160^{\circ}$ con el tubo, liso, superficie interna color amarillo-cremoso, a veces (colección tipo procedente de Costa Rica) con vetas color púrpura, fauces color púrpura, ápice agudo a acuminado; ginostemo 4-5.2 × 3-4 mm; cápsula ca. $4.5 \times 1 \mathrm{~cm}$; semillas no vistas.

Distribución: Costa Rica y Panamá. El presente reporte amplía el rango de la especie al oriente de la zona del Canal. Se espera que existan poblaciones intermedias en Panamá occidental y central. En Panamá crece en bosques pluviales primarios o secundarios, por debajo de 400 $\mathrm{m}$ de elevación.

Ejemplares examinados: PANAMÁ. Colón, río Guanche, along río Guanche 3-7 km above bridge 300700 ft, 01.X.1978, (fl), B. E. Hammel et al. 4913 (MO). Panamá, Serranía de Maje, 360 m, 17.IX.1982, (fl), W. G. D'Arcy 9380 (MO).

\subsubsection{Aristolochia leuconeura Linden, Belgique} Hort. 8: 164. 1858. TIPO: COLOMBIA. Caldas, orillas del río Guarinó entre el retén y La Victoria, 200 m, 27.I.1957, (fl), R. Jaramillo y A. Fernández 715 (neotipo designado por González (1990): COLCOL000001149!). Figs. 4J-M.

$=$ A. veraguensis Klotzsch ex Duch., DC. Prodr. 15: 458. 1864. TIPO: COSTA RICA. “Costa Rica et Veragua”, s.f. (fl), J. von R. Warscewicz 252 (holotipo: B, destruido, lectotipo, aquí designado: MPU-MPU018745!).

$=A$. argyroneura Hoehne ex L. Uribe, Caldasia 7: 160 . 1955. TIPO: COLOMBIA. Tolima, Honda, "en una huerta a orillas del río Gualí (ejemplar cultivado traído de los montes vecinos)", 230 m, IV.1955, (fl, fr), L. Uribe-Uribe 2642 (lectotipo designado por Freitas et al. (2017): COLCOL000001144!, isolectotipos: COL-COL000001143!, NY-NY00285541!). 
Lianas de tallos glabros; peciolo 7-15.5 cm de largo, glabro; lámina ovada, 12-25 × 10-19 cm, neurovariegada (venas color blanco-amarillentas), haz glabra, envés color verde claro, glabrescente a glabro, base profundamente cordado-lobada, no peltada, escotaduras 3-6.4 cm profundidad, ápice agudo a acuminado, venas primarias basales 5(7); racimos hasta $1 \mathrm{~cm}$ de largo; pedúnculo más ovario $3.6-5 \mathrm{~cm}$ de largo; perianto arqueado entre el tubo y el limbo, superficie externa glabrescente, color vináceo a marrón; utrículo elipsoide a obovoide, 9-15 × 5-7 mm; tubo 1-2.5 $\times$ 0.18-0.6 cm, en ángulo obtuso respecto al utrículo; limbo unilabiado, ovado a oblongo, 2-3 × 1-2.4 cm, en ángulo ca. $90^{\circ}$ con el tubo, liso a muy ligeramente papilado, no fimbriado, superficie interna color blanco amarillento con vetas color morado a marrón, fauces color blanco amarillentas, ápice obtuso, mucronado; ginostemo 3.5-6 × 2-3 mm; cápsula $12-20 \times 1-1.5 \mathrm{~cm}$, ligeramente arqueada; semillas ovoides, 3-4 × 2-3 mm, planas, no aladas, recubiertas de un arilo glutinoso en la base y la rafe prominente.

Distribución: Costa Rica, Panamá y Colombia. En Panamá crece en bordes de bosques pluviales primarios y secundarios, por debajo de 100 m de elevación.

Ejemplares examinados: PANAMÁ. Darién, 110 mi from Bayano Dam Bridge, vic. of Canglón, $1 \mathrm{~km} \mathrm{~W}$ of Bridge in Canglón, $50 \mathrm{ft}, 14 . \mathrm{V} .1980$, (st), T. Antonio 4591 (F, MO). Panamá, área del canal, Balboa, Balboa Orchid Garden, originally collected in the vic. of El Real, $10 \mathrm{~m}$, 25.VIII.1941, (fl), P. H. Allen 2210 (MO, US); cerca de las casas del STRI, 21.IX.2002, (st), F. González 4019 (COL, PMA).

Comentarios taxonómicos y nomenclaturales: Linden (1858) se refiere a un ejemplar de Triana (s.n.), procedente de las riberas del río Magdalena, ("La découverte est due â M. Triana, qui la rencontro sur les bords du rio Magdalena, entre Honda et Ambalema"). Debido a que no fue posible encontrar un ejemplar que pudiese corresponder a esta colección original, González (1990) designó como neotipo el ejemplar R. Jaramillo y A. Fernández
715 (COL-COL000001149), recolectado en una localidad cercana a la indicada por Linden (1858). Se designa como lectotipo del binomio Aristolochia veraguensis el ejemplar MPU-MPU018745, el único duplicado existente del holotipo, originalmente depositado en B, y destruido. Recientemente, Barringer (2014) redujo Aristolochia schippii Standl., especie restringida al sur de México y Belice, a la sinonimia de $A$. leuconeura. Aunque cercanamente relacionadas, ya que presentan morfología y dimensiones foliares y capsulares similares, así como racimos caulifloros y semillas con arilo glutinoso en la región calazal, las dos especies difieren claramente en las siguientes características: A. schippii presenta tubo del perianto levemente curvado hacia la parte media, en ángulo ca. $140-160^{\circ}$ con el utrículo; limbo ovado-angosto, 3-5.5 cm de largo, fimbriado en la cara interna y la margen, en ángulo $110-140^{\circ}$ con el tubo, con ápice agudo, no mucronado; y semillas 5-5.5 $\times$ 4-5 mm. En comparación, A. leuconeura presenta tubo del perianto fuertemente curvado y en ángulo obtuso respecto al utrículo; limbo ovado a oblongo, 2-3 cm de largo, liso (no fimbriado) en la superficie interna y la margen, en ángulo ca. $90^{\circ}$ con el tubo, con ápice obtuso, mucronado; y semillas más pequeñas, 3-4 $\times 2-3 \mathrm{~mm}$. Por lo tanto, $A$. schippii se reestablece en el presente trabajo como especie diferente de $A$. leuconeura.

2.2. Aristolochia ser. Thyrsicae. Peciolo y pedúnculo floral con zona basal de abscisión; inflorescencias en cimas (ripidios) con 2-20 flores, cada flor opuesta a una bracteola triangular no perfoliada; cápsulas con septos cancelados; semillas oblongo-anchas, bialadas, el ala abaxial más corta que la adaxial, 7-11 × 12-18 mm, incluidas las alas membranosas de color café claro, semilla propiamente dicha ovoide, $3.5-4.5 \times 3.5-4.6 \mathrm{~mm}$, esparcidamente verrugosa, color negro, rafe linear, promínula, no variables entre las especies de la serie.

2.2.1. Aristolochia chapmaniana Standl., Contr. Arnold Arbor. 5: 60. 1933. TIPO: PANAMÁ. Área del canal, Barbour Point, Barro Colorado Island, 15.XI.1931, (fl), O. Shattuck 413 (holotipo: F- 
F0048793F!, isotipos: MO!, US!, US-US00323950!, US-US01050056!, US-US01050057!). Fig. 5G.

$=$ A. maxima Jacq. var. cordata Standl., Publ. Field Mus. Nat. Hist., Bot. Ser. 8: 136. 1930. TIPO: PANAMÁ. Área del canal, shores of Gatun Lake, south of the Laboratory BCI, 28.VIII.1929, (fl, fr), W. N. Bangham 455 (holotipo: A-A00099222!, isotipo: $F$ !).

Lianas con tallos jóvenes densamente híspidos; peciolo 0.6-0.1 cm de largo, híspido; lámina oblonga a angosta-oblonga, 9-19.5 $\times 4-5.5 \mathrm{~cm}$, base profundamente cordada, escotaduras angostas, hasta $1 \mathrm{~cm}$ de profundidad, ápice agudo a subobtuso, haz esparcidamente híspida, estrigosa, envés densamente híspido especialmente a lo largo de la venación reticulada prominente a promínula; venas primarias basales 3(5); pedúnculo floral esparcidamente pubérulo; bracteolas linear-lanceoladas, 10-15 $\times$ 2-4 mm, esparcidamente pubérulas por el envés; perianto levemente curvado especialmente entre el tubo y el limbo, superficie externa esparcidamente pubérula; utrículo elipsoidal, $25-40(-45) \times 7-10 \mathrm{~mm}$, levemente inequilátero en el extremo distal, tubo recto o levemente refracto, 2.5$3.5 \times 0.3-0.7 \mathrm{~cm}$; limbo ovado-angosto, rara vez ovado, $4-7.5 \times 1.2-1.8 \mathrm{~cm}$, levemente reflexo en el 1/2-1/4 distal, superficie interna color marrón, ápice con un acumen filiforme hasta $1 \mathrm{~cm}$ largo; ginostemo 6-7 × 3-5-4 mm; cápsula 10-12 × 4-4.5 cm.

Distribución: Panamá, Colombia y Ecuador.

Ejemplares examinados: PANAMÁ. Área del canal, shoreline of Miller Península, parallel to Bohío Reach, 5.X.1968, (fl), T. Croat 6733 (SCZ, STRI); Barro Colorado Island, near S - M - Trail, 8.I.1969 (fl), $T$. Croat 6969 (SCZ, STRI); Barro Colorado Island, Shannon 4, 11.II.1989, (fl), N. Garwood 2812 A (SCZ); Barro Colorado Island, 20.IX.2002, (fl, fr), F. González 4017B (COL, PMA); cerro Gordo, near Culebra, 50-290 m, 10.I.1911, (fl), H. Pittier 2304 (BM, GH); Barro Colorado Island, 25.II.1982, (fl), R. J. Schmalzel y L. Brophy
401 (MO). Colón, camino a la zona maderera de Santa Rita, 20.III.1969, (fl), M. D. Correa y R. Dressler 1199 (PMA). Darién, Ensenada del Guayabo, 18 km SE Jaque, ca. 50 m, 12.I.1983, (fl, fr), N. Garwood et al. 167 (BM, MO, PMA). Panamá, Canal Zone, Navy Reservation, N of Gamboa, 21.II.1964, (fl), R. Dressler 2893 (CONN, PMA); cerro Campana, 19.IV.1971, (fl, fr), R. Dressler y N. H. Williams 3956 (CONN, PMA); San José Island, Perlas archipelago, Gulf of Panamá, about 55 miles SSE of Balboa, 24.I.1946, (fl, fr), I. M. Johnston 1253 (GH).

Comentarios taxonómicos y nomenclaturales: Aristolochia chapmaniana fue reducida a la sinonimia de $A$. tonduzii por Barringer (1983). Aunque González (1990) y más recientemente Barringer (2014) aceptaron dicha sinonimia, en el presente trabajo (véase también González y Pabón-Mora, 2017) restablecen A. chapmaniana como especie diferente, debido a caracteres diferenciales consistentes en la morfología y tamaño del perianto.

2.2.2. Aristolochia maxima Jacq., Enum. Syst. Pl. 30. 1760. TIPO: COLOMBIA. (Lectotipo designado por González (1990): Jacquin, 1763 (iconografía)). Figs. $5 \mathrm{~A}-\mathrm{F}$.

$=$ A. geminiflora Kunth, Nov. Gen. Sp. Pl. 2: 148, t. 117. 1817. TIPO: COLOMBIA. "Crescit prope Honda in via ad urbem Guaduas, 170 hex. Floret Junio", sin fecha precisa (fl), A. Bonpland 1699 (lectotipo, aquí designado: P-P00669999!, isolectotipos: P-P00152025!, P-P00152026!).

=A. oblongifolia Brandegee, Univ. Calif. Publ. Bot. 10: 404. 1924. TIPO: MÉXICO. Chiapas, Hacienda Monserrate, IX.1923, (fl), C. A. Purpus 9076 (holotipo: UCUC220393!, isotipo: CAS-CAS0313718).

Lianas de tallos pubérulos; peciolo $0.7-2.8 \mathrm{~cm}$ de largo; lámina obovada, oblongo-angosta u oblonga, 5-25 $\times 2.5-11.6 \mathrm{~cm}$, base truncada a ligeramente cordada, escotaduras casi siempre ausentes, cuando presentes $<1.5$ $\mathrm{cm}$ de profundidad, ápice cortamente acuminado, agudo, 

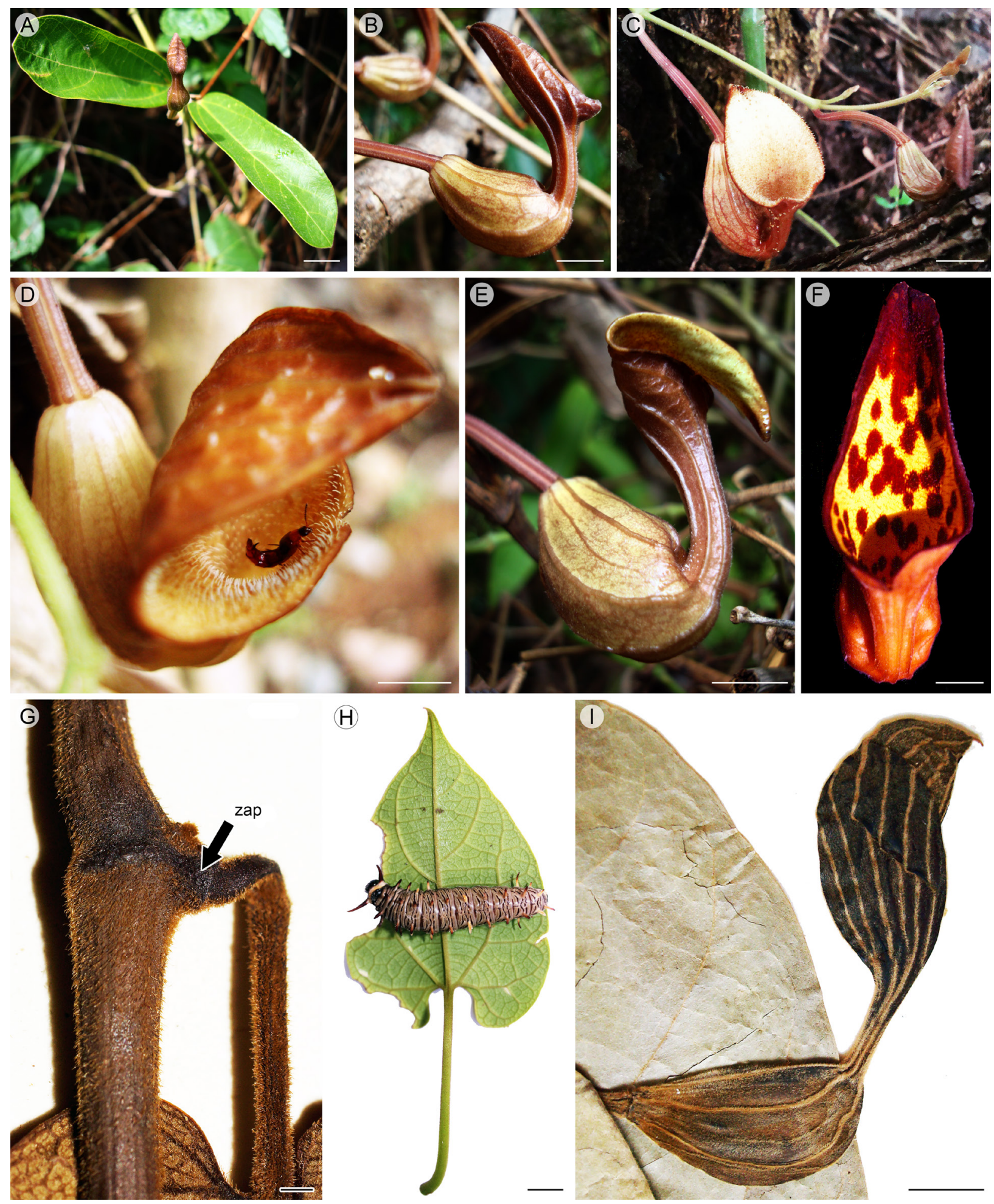

Figura 5: Especies de Aristolochia ser. Thyrsicae F. González presentes en Panamá. A-F. Aristolochia maxima Jacq. (González et al. 4018, COL) A. hojas y botón floral; B. flor en preantesis, vista lateral; C. porción de un ripidio caulifloro; D. flor en antesis visitada por un coleóptero de la familia Staphylinidae; E. flor en antesis tardía, vista lateral; F. flor de un ripidio caulifloro, vista frontal; G. Aristolochia chapmaniana Standl. (González 4017B, COL), nudo y zona de abscisión en la base del peciolo (zap); H. Aristolochia sprucei Mast. (González 4020B, COL) y oruga de Battus sp. luego de su cuarta muda; I. Aristolochia tonduzii O.C. Schmidt (Dressler 4344, CONN), flor prensada y seca, vista lateral. Escalas: $1 \mathrm{~cm}$ en A-C, E, H; 5 mm en D, F; 1 mm en G; 2 cm en I. 
obtuso, redondeado o a veces levemente emarginado, haz glabrescente, envés pubérulo, venas primarias basales 3; ripidios axilares a hojas distales con el raquis hasta $10 \mathrm{~cm}$ de largo, paucifloras, una sola yema axilar desarrollada por cada nudo florífero, o basicaules (cauli- o pseudocaulinares), muy ramificados y densifloros, con raquis hasta $1 \mathrm{~m}$ de largo y dos yemas axilares desarrolladas por cada nudo; pedúnculo más ovario hasta $4.7 \mathrm{~cm}$ de largo; perianto geniculado entre cada una de sus partes, superficie externa pubérula; utrículo obovoide, $15-33 \times 6-17 \mathrm{~mm}$, tubo 1-2 $\times 0.3-0.8 \mathrm{~cm}$, en ángulo ca. $90^{\circ}$ con el utrículo, limbo unilobado, ovado, 2.5-4.5(-5) × 2-3.5 cm, en ángulo ca. $90^{\circ}$ con el tubo, superficie interna color marrón, a veces con vetas o manchas color amarillo, base redondeada, ápice subagudo, a veces ligeramente emarginado o mucronulado, mucrón hasta $1 \mathrm{~mm}$ de largo; ginostemo 4-6 × 3.5-5.5 mm; cápsulas 5.5-12 × 3.5-5 cm, por lo general formadas a partir de la flores de las cimas distales, muy rara vez a partir de flores de las cimas caulifloras.

Distribución: Estados Unidos de América (Florida), México, Centro América (Guatemala, Belice, Honduras, El Salvador, Nicaragua, Costa Rica, Panamá), Colombia y Venezuela. Su presencia en Cuba y Martinica puede ser debida a introducción reciente. En Panamá crece en bordes de bosques secundarios húmedos o secos, $\mathrm{y}$ en matorrales secos, por debajo de 1000 m de elevación.

Ejemplares examinados: PANAMÁ. Darién, Ensenada del Guayabo, 18 km SE Jaque, ca. 50 m, 12.I.1983, (fl), N. Garwood et al. 168 (BM). Panamá, Isla de Taboga, sur de la ciudad de Panamá, camino al este de playa Diablo, 12.XII.1986, (fr), M. D. Correa y J. Aranda 4692 (MO, PMA); BCI, 25.VII.1960, (fr), J. E. Ebinger 601 (F); Parque Natural Metropolitano, colectada desde el dosel de la grúa del STRI, s.f. (fr), C. Galdames et al. 5169 (NY, PMA); Taboga Island, 15.VIII.1972, (fr), A. Gentry 5734 (F, GH, MO); Parque Nacional Metropolitano, 21.IX.2002, (fl, fr), F. González et al. 4018 (COL, PMA), from Gatun Lake on the road from Gamboa before Paraíso, s.f. (st), A. Hladik 367 (MO); Bellavista, 25.II.1923, (st), F. MacBride 2763 (F, G); vic. cerro Jefe, 650 m, ca. 9¹5'N, 79³0'W, 27.VIII.1986, (fr), G. McPherson 9994 (MO); ca. $100 \mathrm{~m}$ de la barriada La Locería, hacia los autocines, 17.XI.1974, (fl), M. Miranda 39 (F, MO, PMA); Parque Natural Metropolitano, colectado desde la grúa, dosel a ca. $30 \mathrm{~m}$ alto, 21.XI.1995, (fl, fr), F. Ødegaard s.n. (STRI); Sabanas, north of Panama City, sin fecha (st), Bro. Paul 517 (US); Parque Metropolitano, 30.XI.1999, (fl), S. Sakai 535 (PMA); Taboga Island, XII.1923, (st), P. C. Standley 27090 (US); Taboga Island, XII.1923, (st), P. C. Standley 27856 (US); Tumba Muerto road, near Panamá, 6.I.1924, (fr), P. C. Standley 29804 (US); between Las Sabanas and Matías Hernández, 21.I.1924, (fr), P. C. Standley 31839 (US); Curundú nr. Survival School, ETC label 1001 (US Army Tropic Test Center, Fort Clayton, Canal Zone, 8.II.1966), 24.VI.1966, (fr), E. L. Tyson 4179 (MO, STRI); along road to cerro Azul at app. $700 \mathrm{ft}$, 5.III.1972, (fr), E. Tyson y R. L. Lazor 6168 (MO); Barro Colorado Island, Canal Zone Biological Area, S.I. Vigue Beach, Arrajan, 10.I.1952, (st), J. Zetek 5582 (MO). San Blas, through cultivation in mainland in front of Ustupo, 9.XI.1975, (fl), W. D'Arcy 9484 (MO).

Comentarios taxonómicos y nomenclaturales: Jacquin $(1760,1763)$ no refirió ningún ejemplar original como base para la descripción de Aristolochia maxima. González (1990) designó como lectotipo la lámina 146 de la obra de Jacquin (1763) Select. Stirp. Amer. Hist. 233.

Existen tres pliegos correspondientes a la colección original de Aristolochia geminiflora (Bonpland 1699), por lo cual se requiere designar un lectotipo; se designa el pliego P-P00669999, debido a que, además de haber sido verificado por Kunth y recolectado en Honda (Tolima, Colombia), es el más completo ya que posee una inflorescencia y una flor, además de las hojas características.

2.2.3. Aristolochia sprucei Mast., Fl. Bras. (Martius) 4(2): 88. 1875. TIPO: BRASIL. "Crescit in prov. do Alto Amazonas, São Gabriel, capoeiras”, III.1852, (fl), R. Spruce 2223 (holotipo: K-K000323540!, isotipo: P!). Fig. 5H. 
= A. securidata Mast., Bot. Gaz. 33: 256. 1902. TIPO: COSTA RICA. Rosario, llanuras de Santa Clara, Cost., 300 m, VII.1899, (fl), H. Pittier 7604 (lectotipo, aquí designado: US-US00105878!, isolectotipo: G!).

= A. macbrideana Standl., Publ. Field Mus. Nat. Hist., Bot. Ser. 13(2): 438. 1937. TIPO: PERÚ. San Martín, Chazuta, río Huallaga, ca. 260 m, IV.1935, (fl), G. Klug 4079 (holotipo: F-F0042311F!, isotipos: BMBM000040884!, CAS-CAS0000539, GH-GH00099220!, K-K000323626!, NY-NY00285553!，S，S-R-392!，UCUC710185!, US-US00105851!).

Bejucos de tallos esparcidamente adpreso-pubérulos; peciolo 4-13 cm de largo; lámina ovada, 8-20(-26) × $5-13(-18) \mathrm{cm}$, base profundamente cordado-lobada, escotaduras $1-5 \mathrm{~cm}$ de profundidad, ápice agudo o acuminado, haz usualmente glabrescente, lisa, envés por lo general densamente adpreso-pubérulo en las aréolas y esparcidamente adpreso-pubérulo en las venas, venas primarias basales 5; ripidios hasta $21 \mathrm{~cm}$ de largo, con 10 o más entrenudos, cada uno hasta $2 \mathrm{~cm}$ largo; bracteolas 1.5-5(12) $\times 1-4(-10) \mathrm{mm}$; pedúnculo más ovario hasta $1.8 \mathrm{~cm}$ de largo; perianto levemente curvado, superficie externa pubérula; utrículo obovoide, $8-20 \times 3-5 \mathrm{~mm}$; tubo 1-3(4) $\times$ 0.1-0.6 cm, en ángulo ca. $180^{\circ}$ con el utrículo; limbo unilabiado, ovado a oblongo, 2.5-4(-5) $\times 1.2-2.6 \mathrm{~cm}$, en ángulo $140-160^{\circ}$ con el tubo, superficie interna color marrón claro, a veces con manchas color amarillo, ápice obtuso y con frecuencia mucronado; ginostemo $3.5-5 \times$ 1.5-2.8 mm; cápsula 5-8 × 4-5.5 cm.

Distribución: Centro América (Honduras, Nicaragua, Costa Rica, Panamá), Colombia, Venezuela, Guyana, Ecuador, Perú, Brasil y Bolivia. En Panamá crece en bordes de bosques primarios o secundarios en buen estado de conservación, por debajo de 1400 m de elevación.

Ejemplares examinados: PANAMÁ. Bocas del Toro, alrededor del campamento de IRHE, 16.XII.1979, (fl, fr), L. Carrasquilla y R. Mendoza 1164 (MO, PMA); orillas del Changuinola, bosque alrededor de Corrien- te Grande, 25.II.1980, (fr), M. D. Correa et al. 3958 (MO, PMA); along road between Almirante and Ojo de Agua 3-6 km W of Almirante, 30-200 m, 4.VIII.1976, (fl, fr), T. Croat 38194 (MO, PMA); above Almirante on road to Changuinola, 0-200 m, 3.IV.1977, (fl, fr), W. G. D'Arcy 11228 (MO); hillside above Almirante, 28.XI.1971, (fr), A. Gentry 2680 (MO, PMA); near Río San Pedro, 8.I.1975, (fr), B. L. Gordon 17 a (MO); Changuinola to $5 \mathrm{mi} \mathrm{S}$ at junction of ríos Changuinola and Terebe, 100-200 ft., s.f. (fr), W. H. Lewis et al. $793 \mathrm{~A}$ (MO); along road to Chiriquí Grande, 10 road miles from continental divide, ca. 2 road miles, along road $\mathrm{E}$ of highway, $08^{\circ} 55^{\prime} 04^{\prime \prime N}, 82^{\circ} 10^{\prime} 04^{\prime \prime W}, 300$ m, 9.II.1987, (fr), G. McPherson 10439 (MO); vic. Chiriqui Lagoon, 2.X.1940, (fl), H. von Wedel 1002 (MO); vic. Chiriqui Lagoon, 15.X.1940, (fl), H. von Wedel 1201 (GH, MO); idem, 19.X.1940, H. von Wedel 1247 (GH, MO, US); Water Valley, vic. Chiriqui Lagoon, 5.XI.1940 (fl), H. von Wedel 1499 (GH); vic. Chiriquí Lagoon, 19.XII.1940, (fl), H. von Wedel 1841 (GH, MO, NY). Coclé, Distrito Penonomé, road from Churuquita Grande to Caimito, $380 \mathrm{~m}, 8^{\circ} 40^{\prime} \mathrm{N}, 80^{\circ} 12.01^{\prime} \mathrm{W}, 22 . \mathrm{I} .2005$ (fl, fr), M. Blanco y D. Penneys 2861 (FLAS, MO); at edge of road cut leading to sawmill ca. $12 \mathrm{mi}$ from Llano Grande, 200 m, $8^{\circ} 47^{\prime} \mathrm{N}, 80^{\circ} 28^{\prime} \mathrm{W}, 17 . X I I .1983$, (fl, fr), H. W. Churchill et al. 4143 (MO); road from La Pintada to Coclesito, $8^{\circ} 45^{\prime} \mathrm{N}, 80^{\circ} 30^{\prime} \mathrm{W}$, ca. $600 \mathrm{~m}, 7 . I I .1983$, (fr), C. Hamilton y G. Davidse 2804 (MO). Colón, cerro Santa Rita, ca. 6 mi from the Transisthmian hwy, 800-900 ft, 13.IX.1979, (fr), T. Antonio 1777 (F, MO); Santa Rita, al E de la zona montañosa en el camino a zona maderera, 16.I.1969, (fl, fr), M. D. Correa y R. L. Dressler 1105 (COL, PMA); camino entre la estación climatológica de Agua Clara y Puerto Pilón, 20.III.1969, (st), M. D. Correa y R. L. Dressler 1197 (PMA); ca. 5 mi SW of Portobello, 7.IV.1971, (fr), T. Croat 14179 (MO); Portobello Road, ca. $5 \mathrm{mi}$ E of Boyd Roosevelt Highway, less than $30 \mathrm{~m}, 9^{\circ} 17^{\prime} \mathrm{N}, 7^{\circ} 37^{\prime} \mathrm{W}, 20 . I .1990$, (fr), T. Croat 69866 (MO, PMA); Prov. Canal Area, 26 to $140 \mathrm{~m}$ to $9 \mathrm{mi}$ from Gamboa Gate, 19.III.1985, (fr), $W$. G. D'Arcy et al. 16079 (MO); Santa Rita Lumber road, 
ca 15 km E of Colón, 7.II.1971, (fl, fr), R. Dressler 3929 (CONN, MO, PMA); Santa Rita lumber road, $8.1 \mathrm{~km}$ E of Transisthmian highway, 15.VI.1977, (fl, fr), J. P. Folsom 3683 (MO, PMA); Santa Rita Ridge, E of Transisthmian highway, 300-500 m, 20.IX.1972, (fl, fr), $A$. Gentry 6087 (F, MO, NY, SCZ, STRI, WAG); Santa Rita Ridge, 3-5 mi from highway, 23.V.1972 (fr), A. Gentry et al. 9545 (PMA); Santa Rita, este de Colón, II.1968, (st), A. Gómez-Pompa et al. 3011 (MEXU); Santa Rita, 22.IX.2002, (st), F. González 4020B (COL, PMA). Panamá, Parque Nacional Altos de Campana, 800-900 m, $8^{\circ} 40^{\prime} \mathrm{N}, 7^{\circ} 55^{\prime} \mathrm{W}, 9 . X I I .1993$, (fl, fr), M. D. Correa y E. Montenegro 10221 (PMA, SCZ, STRI); Altos de Campana, $8^{\circ} 40^{\prime} \mathrm{N}, 7^{\circ} 55^{\prime} \mathrm{W}, 11 . \mathrm{V} .1995$, (fl, fr), M. D. Correa y E. Montenegro 11108 (PMA, SCZ, STRI); El Llanto, Carti highway, about $19 \mathrm{~km} \mathrm{~N}$ of El Llano, 20.II.1974, (fl), R. L. Dressler 4601 (PMA); cerro Campana, 26002800 ft, 4.VI.1967, (fr), W. H. Lewis et al. 1971 (MO, NY, WAG); El Llano - Carti road, $17.5 \mathrm{~km}$ from Inter - American hwy, 350 m, 14.II.1975, (fr), S. Mori et al. 4621 (MO). San Blas, Comarca de San Blas, Nusgandi, El Llano-Carti road, $19.1 \mathrm{~km}$ from Interamerican hwy, $9^{\circ} 19^{\prime} \mathrm{N}, 78^{\circ} 55^{\prime} \mathrm{W}, 350$ m, 6.IX.1984, (fr), G. de Nevers 4200 (MO, PMA). Veraguas, Mts. 3-5 mi N of Santa Fe, 500-1000 m, 12.XII.1971, (fl), A. Gentry 3017 (AAU, F, MO, PMA); carretera hacia Santa Fe y Alto de Piedra, 14.VIII.1994, (fr), E. Montenegro 1049 (PMA).

Comentarios taxonómicos y nomenclaturales: E1 estudio detallado del material tipo y la descripción original de Aristolochia securidata no revela caracteres que diferencien este binomio de $A$. sprucei, por lo cual se confirma la redución de este binomio a la sinonimia, propuesta por Barringer (2014). Existen dos pliegos del material original de A securidata, depositados en G y US; se designa este último como lectotipo, ya que es el más completo.

2.2.4. Aristolochia tonduzii O.C. Schmidt, Repert. Spec. Nov. Regni Veg. 23: 284. 1927. TIPO: COSTA RICA. "Forets de Trepos, Las Vueltas, Tucurrique", 700 m,
2.V.1899, (fl, fr), A. Tonduz 13175 (holotipo: B, destruído, lectotipo designado por Barringer (1983): CR, isolectotipos: G-G00237227!, P-P00350475!, P-P00350476!, US-US0026826!). Fig. 5I.

= A. translucida Pfeifer, Brittonia 28: 349. 1976. Barringer, Fieldiana Bot., New ser. 13: 86. 1983. TIPO: COSTA RICA. Finca La Selva, VIII.1970, (fl), A. M. Young 3 (holotipo: CONN!).

= A. pfeiferi Barringer, Brittonia 35: 171. 1983. TIPO: PANAMÁ. Colón: Santa Rita Ridge, 23.III.1972, (fl), $A$. Gentry y J. D. Dwyer 4810 (holotipo: F-F0048800F!, isotipos: GH!, GH-GH00035995!, MO!).

Lianas con tallos hirsuto-pubérulos; peciolo 1.2$5(-6) \mathrm{cm}$ de largo, hirsuto pubérulo; lámina oblonga, ovado-angosta o, a veces, elíptica, elíptica-ancha u ovada, $6-17.5(-23) \times 4-8(-15) \mathrm{cm}$, cartácea a coriácea, base cordado-lobada, escotaduras $0.5-3 \mathrm{~cm}$ de profundidad, a veces truncada, ápice obtuso a cortamente acuminado, haz por lo general esparcidamente hirsuta-velutina, estrigosa, tricomas fácilmente caedizos dejando una superficie áspera, envés densamente hirsuto-pubérulo especialmente sobre las venas, a veces glabrescente, venas primarias basales 5; ripidios hasta $11 \mathrm{~cm}$ de largo, con entrenudos 1-2 $\mathrm{cm}$ de largo; bracteolas hasta $8 \times 4 \mathrm{~mm}$; pedúnculo más ovario 2.5-3.5 cm de largo, densamente hirsuto-pubérulo; perianto levemente curvado entre el utrículo y el tubo, superficie externa densamente recubierta de indumento ferrugíneo, hirsuto-pubérulo; utrículo elipsoide, 28-50(70) $\times 13-18 \mathrm{~mm}$; tubo levemente curvado formando un ángulo de $130-160^{\circ}$ con el utrículo, 20-50 × 2-6 mm; limbo unilabiado, ovado-ancho a oblongo-ancho, (4-)5-7 $\times$ 2-4 cm, cuculado, superficie interna color marrón, en ángulo ca. $180^{\circ}$ con el tubo, papilado especialmente en la superficie interna, ápice agudo; ginostemo 5-7 × 3-4.5 $\mathrm{mm}$; cápsula 5-8.5 × 3-4 cm, híspida cuando indehiscente, luego glabrescente.

Distribución: Centro América (Nicaragua, Costa Rica y Panamá). En Panamá crece en bordes de bosques 
primarios o secundarios en buen estado de conservación, por debajo de $800 \mathrm{~m}$ de elevación.

Ejemplares examinados: PANAMÁ. Colón, hills just $\mathrm{N}$ of the río Guanche, 1-200 m, 16.XI.1975, (fr), $G$. Davidse y W. G. D'Arcy 10075 (MO); lower río Guanche, 18.IV.1973, (fl), R. Dressler 4344 (CONN, PMA). Panamá, ca. $\mathrm{km} 5$ de la carretera Llano - Carti, $425 \mathrm{~m}, 9^{\circ} 17^{\prime} \mathrm{N}$, 78'58'W, 425 m, 1.VII.1994, (fr), C. Galdames et al. 1216 (PMA, SCZ, STRI); El Llano - Cartí road, 4-5 mi from PanAmerican hwy, tropical wet forest, $250 \mathrm{~m}, 7$. V.1981, (fr), K. Sytsma y L. Andersson 4431 (F).

\section{Nombres dudosos}

1. Aristolochia mathewsii Duch. fue descrita por Duchartre (1864) para reemplazar el nombre $A$. reticulata Seem. (Seemann, 1854), homónimo posterior de A. reticulata Nutt. La especie propuesta por Seemann fue descrita con base en dos sintipos, uno recolectado en Panamá ("David, Province of Veraguas" Seemann s.n., K) y otro en Perú (Tarapoto, Mathews 1302 (BM, $\mathrm{K}-\mathrm{K} 000323624)$. El primer ejemplar parece corresponder a A. chapmaniana. El segundo ejemplar carece de flores, pero sus hojas son muy similares a la especie peruana $A$. fragrantissima. Desafortunadamente, la identificación de estos ejemplares no es conclusiva.

2. Aristolochia constricta Griseb., Abh. Königl. Ges. Wiss. Göttingen 7: 225. 1857. TIPO: GUADALUPE. "In margine sylvarum pr. Morne", sin fecha (fl), E. P. Duchassaing s.n. (holotipo: GOET-GOET000271). Esta especie fue recientemente revalidada por Barringer (2014), quien redujo a la sinonimia de la misma a $A$. sprucei. La descripción original de $A$. constricta menciona la presencia de "estípulas" (pseudoestípulas) deciduas y flores axilares, solitarias, rasgos que no coinciden con los del ejemplar tipo, recolectado por el médico y naturalista francés E. P. Duchassaing de Fontbressin (1818-1873) en la isla caribeña de Guadalupe, el cual carece de pseudoestípulas y posee una in- florescencia cimosa con por lo menos 3 nudos floríferos. Duchassaing recolectó plantas en Guadalupe entre 1840-1848 y entre 1850-1852, además de colecciones efectuadas en Panamá en 1851 (Lanjouw y Stafleu, 1954). Llama la atención que, desde entonces, no ha sido recolectado un ejemplar similar al ejemplar tipo de $A$. constricta en Guadalupe, y que Grisebach (1857) señalara en la descripción original de $A$. constricta que ésta es similar a $A$. anguicida, especie que sí posee pseudoestípulas y flores axilares, solitarias, y que además, es frecuente en varias islas del Caribe. Debido a la incertidumbre taxonómica generada por lo antes expuesto, se recomienda que el binomio $A$. constricta no sea empleado.

Especie excluída: La presencia de Aristolochia nummularifolia Kunth in Panamá, reportada por Pfeifer (1960), continúa sin ser confirmada. Hasta ahora, todos los registros de esta especie se limitan a los Llanos Orientales de Colombia y los Llanos de Venezuela. Aunque es improbable que A. nummularifolia se encuentre en Panamá, se incluyen aquí varias fotografías de sus caracteres diagnósticos, incluidos el porte herbáceo, las raíces con cortos engrosamientos napiformes, las hojas reniformes, diminutas $(9-35 \times 12-34 \mathrm{~mm})$, las flores longilineares $<2$ cm de largo, y las cápsulas obladas, 4-6 × 6-9 mm, oligospermas (Fig. 6). Los órganos vegetativos y reproductivos de esta especie están dentro de los más pequeños en todo el género.

\section{AgradeCIMIENTOS}

Al personal científico de los herbarios de la Universidad de Panamá (PMA) y del Smithsonian Tropical Research Institute (SCZ, STRI) y por su colaboración durante la visita del primer autor a dichas instituciones. A Kanchi Gandhi (Universidad de Harvard) por su colaboración en la decisión nomenclatural respecto a Aristolochia trilabiata. Al personal de curaduría del herbario $\mathrm{C}$ (Copenhagen, Dinamarca), en particular a Olof Ryding, por reubicar y poner a disposición para el presente estudio el ejemplar tipo de A. trilabiata. A Barry Hammel, Jan Meerman, 

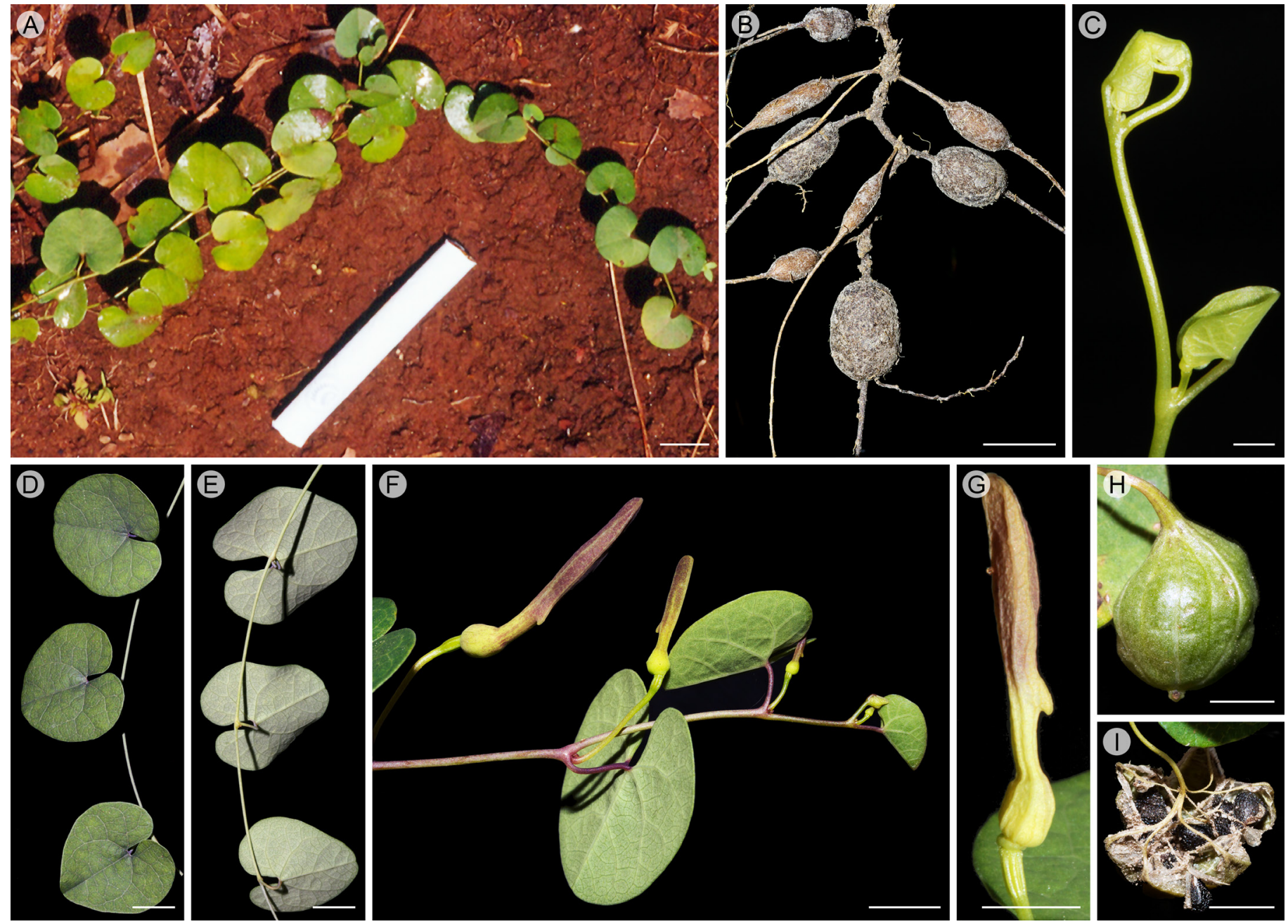

Figura 6: Aristolochia nummularifolia Kunth (González 4675, COL, recolectada en Colombia, departamento de Casanare, municipio de Yopal, 150 m de elevación). A. hábito; B. raíces; C. ápice de un vástago; D-E. hojas por haz (D) y envés (E); F. rama florífera; G. flor, vista lateral; H-I. cápsula antes $(\mathrm{H})$ y después (I) de dehiscencia. Escalas: $1 \mathrm{~cm}$ en A, B; $2 \mathrm{~mm}$ en C; $5 \mathrm{~mm}$ en D-I.

Betzabeth Henríquez y Gordon McPherson (Missouri Botanical Garden) por permitirnos la publicación de las fotografías de $A$. cruenta y A. trilabiata, aquí publicadas. A dos revisores anónimos, cuyas observaciones permitieron mejorar varios aspectos del manuscrito. A Sebastián González (Universidad Nacional de Colombia) por tomar las fotografías de A. nummularifolia.

\section{CONTRIBUCIÓN DE AUTORES}

Los autores contribuyeron por igual al presente trabajo, excepto por el trabajo de campo efectuado en su totalidad por el primer autor.

\section{FINANCIAMIENTO}

El presente trabajo recibió financiación parcial de la Universidad Nacional de Colombia, Sede Bogotá, y de la Universidad de Antioquia.

\section{LITERATURA CITADA}

Ahumada, L. Z. 2010. Aristolochiaceae. In: Ramella, L. L. y P. Perret (eds.). Flora del Paraguay, fasc. 41. Conservatoire et Jardin Botaniques, Ville de Genève. Ginebra, Suiza. Pp. $1-74$.

Barringer, K. 1983. Notes on Central American Aristolochiaceae.

Brittonia 35: 171-174. 
Barringer, K. 2014. Aristolochiaceae. In: Davidse, G., M. Sousa S., S. Knapp y F. Chiang (eds.). Flora Mesoamericana. E-version http://www.tropicos.org/docs/meso/aristolochiaceae espa\%C3\%B1ol.pdf. (consultado julio de 2017).

Basset, Y., H. Barrios, S. Segar, R. B. Srygley, A. Aiello, A. D. Warren, F. Delgado, J. Coronado, J. Lezcano, S. Arizala, M. Rivera, F. Pérez, R. Bobadilla, Y. López y J. A. Ramírez. 2015. The butterflies of Barro Colorado Island, Panama: Local extinction since the 1930s. PLoS One 10(8): e0136623. DOI: https://doi.org/10.1371/journal. pone. 0136623

Blanco, M. A. 2002. Aristolochia gorgona (Aristolochiaceae), a new species with giant flowers from Costa Rica and Panama. Brittonia 54(1): 30-39. DOI: https://doi. org/10.1663/0007-196X(2002)054[0030:AGAANS]2.0. $\mathrm{CO} ; 2$

Blanco, M. A. 2005. Un híbrido espontáneo entre Aristolochia gorgona y A. grandiflora (Aristolochiaceae). Lankesteriana 5(2): 115-118. DOI: http://dx.doi. org/10.15517/lank.v5i2.19802

Croat, T. B. 1978. Flora of Barro Colorado Island. Stanford University Press. Stanford, USA. Pp. 1-921.

Duchartre, P. 1854. Tentamen methodicae divisionis generis Aristolochia, additis descriptionibus complurium novarum specierum novique generis Holostylis. Annales des Sciences Naturelles, 4a. sér. 2: 29-76.

Duchartre, P. 1864. Aristolochiaceae- In: Candolle, A. P. (ed.). Prodromus systematis naturalis regni vegetabilis, pars 15, sect. 1. Victor Masson e hijos. Paris, France. pp. 433-439. DOI: http://dx.doi.org/10.5962/bhl.title.286

Freitas, J., E. J. de Lirio, F. González, V. Bento Sarnaglia Junior y A. Alves-Araújo. 2017. Notes on taxonomy and nomenclature of the F. C. Hoehne's names to Aristolochia (Aristolochiaceae). Phytotaxa 307(1): 64-74. DOI: http:// dx.doi.org/10.11646/ phytotaxa.307.1.6.

Glaziou, A. F. M. 1911. Aristolochia trilabiata. Bulletin de la Societé Botanique de France 58, Mém. 3f: 578.

González, F. 1990. Aristolochiaceae. Flora de Colombia. Monografía No. 12. Instituto de Ciencias Naturales, Universidad Nacional de Colombia. Bogotá, Colombia. $184 \mathrm{pp}$.
González, F. 1991. Notes on the systematics of Aristolochia subsect. Hexandrae. Annals of the Missouri Botanical Garden 78(2): 497-503.

González, F. 1994. Aristolochiaceae. In: Harling, G. G. y L. Andersson (eds.). Flora of Ecuador. Monograph No. 51. Council for Nordic Publications in Botany. Copenhagen, Dinamarca. Pp. 1-42.

González, F. 1997. Hacia una filogenia de Aristolochia y sus congéneres neotropicales. Caldasia 19(1-2): 93-108.

González, F. 1999a. A phylogenetic analysis of the Aristolochioideae (Aristolochiaceae). Ph D. dissertation. City University of New York. Ney York, USA. Pp. 1-352.

González, F. 1999b. Inflorescence morphology and the systematics of Aristolochiaceae. Systematics and Geography of Plants 68(1/2): 159-172. DOI: http://dx.doi. org/10.2307/3668598

González, F. y G. Lozano-Contreras. 2014. Aristolochiaceae. Flora de la Real Expedición Botánica al Nuevo Reyno de Granada. Vol. XXXV. Instituto Colombiano de Antropología e Historia (ICAN), Bogotá, y Real Jardín Botánico de Madrid, España. Bogotá, Colombia. Pp. 21-30.

González, F., J. C. Ospina y C. Zanotti. 2015. Sinopsis y novedades taxonómicas de la familia Aristolochiaceae para la Argentina. Darwiniana, nueva serie 3(1): 38-64.

González, F. y N. Pabón-Mora. 2017. Aristolochia keratuma (Aristolochiaceae), nueva especie de Aristolochia serie Thyrsicae del Chocó (Colombia) y clave de identificación para sus especies. Caldasia 39(1): 50-58. DOI: https:// dx.doi.org/10.15446/caldasia.v39n1.63168

González, F. y P. J. Rudall. 2003. Structure and development of the ovule and seed in Aristolochiaceae, with particular reference to Saruma. Plant Systematics and Evolution 241(3-4): 223-244. DOI: http://dx.doi.org/10.1007/ s00606-003-0050-x

González, F., S. T. Wagner, K. Salomo, L. Symmank, M. S. Samain, S. Isnard, N. P. Rowe, C. Neinhuis y S. Wanke. 2014. Present trans-pacific disjunct distribution of Aristolochia subgenus Isotrema (Aristolochiaceae) was shaped by dispersal, vicariance and extinction. Journal of Biogeography 41(2): 380-391. DOI: http://dx.doi. $\operatorname{org} / 10.1111 /$ jbi.12198 
Green, M. L. 1929. Aristolochiaceae. Proposals by British Botanists. Wyman and Sons. Londres, Reino Unido. P. 186.

Hilje, L. 1984. Fenología y ecología floral de Aristolochia grandiflora Swartz (Aristolochiaceae) en Costa Rica. Brenesia 22: 1-44.

Hoehne, F. C. 1942. Aristolochiáceas. Flora Brasilica 15(2): $1-141$.

Hooker, W. J. 1846. Aristolochia gigantea. Botanical Magazine 72: tabla 4221.

Howard, R. A. 1988: Charles Wright in Cuba 1856-1867. Chadwyck-Healey. Alexandria, USA. Pp. 1-90.

Huber, H. 1985. Samenmerkmale und Gliederung der Aristolochiaceen. Botanische Jahrbücher für Systematik, Pflanzengeschichte und Pflanzengeographie 107: 277-320.

Jacquin, N. J. 1760. Enumeratio Systematica Plantarum. Leiden, Holanda. Pp. 1-41.

Jacquin, N. J. 1763. Selectarum Stirpium Americanarum Historia. Ex Oficina Krausiana. Viena, Austria. Pp. 1-284.

Jacquin, N. J. 1780. Selectarum Stirpium Americanarum Historia. 2a ed. Viena, Austria. Pp. 1-264.

JSTOR, 2017. JSTOR Global Plants: https://plants.jstor. org/ collection/TYPSPE (consultado junio de 2017).

Kunth, C. S. 1817. Asarinae. Nova Genera et Species Plantarum 2: 145-149.

Lanjouw, Ph. D. y F. A. Stafleu. 1954. Index Herbariorum, part II, Collectors. Regnum Vegetabile 2(1): 1-174.

Linden, J. 1858. Aristolochia leuconeura Linden. La Belgique Horticole 8: 165.

Linden, J. J. y E. F. André. 1870. Aristolochia clypeata Linden \& André. Illustration Horticole 17: 223, t. 40.

Lindley, J. 1836. Aristolochia foetens Lindl. Edwards's Botanical Register 21: t. 1824.

Linneo, C. 1767. Systema Naturae, per Regna Tria Naturae. Ed. 12, Vol. 2. Estocolmo, Suecia. Pp. 1-736.

Martius, C. F. P. y J. G. Zuccarini. 1824. Aristolochia gigantea. Flora 7(1): 139.

McNeill, J., F. R. Barrie, W. R. Buck, V. Demoulin, W. Greuter, D. L. Hawksworth, P. S. Herendeen, S. Knapp, K. Marhhold, J. Prado, W. F. Prud'homme van Reine, G. F. Smith, J. H. Wiersema y N. J. Turland (eds.). 2012. International Code of Nomenclature for algae, fungi and plants (Melbourne
Code): adopted by the Eighteenth International Botanical Congress Melbourne, Australia, July 2011. Regnum Vegetabile 154. Königstein: Koeltz Scientific Books.

Ohi-Toma, T. y J. Murata. 2016. Nomenclature of Isotrema, Siphisia, and Endodeca, and their related infrageneric taxa of Aristolochia (Aristolochiaceae). Taxon 65: 152-157.

Pfeifer, H. W. 1960. Aristolochiaceae. In: Woodson, R. E. y R. W. Schery (eds.). Flora of Panama. Annals of the Missouri Botanical Garden 47: 309-323.

Pfeifer, H. W. 1966. Revision of the North and Central American hexandrous species of Aristolochia (Aristolochiaceae). Annals of the Missouri Botanical Garden 53: 115-196.

PMA. 2017. Herbario virtual http://herbario.up.ac.pa/Herbario/ herb/vasculares/view/family/Aristolochiaceae. (consultado mayo de 2017).

Rankin Rodríguez, R. y W. Greuter. 1999. Charles Plumier's drawings of American plants and the nomenclature of early Caribbean Aristolochia species (Aristolochiaceae). Taxon 48(4): 677-688. DOI: http://dx.doi.org/10.2307/1223639

Sakai, S. 2002. Aristolochia spp. (Aristolochiaceae) pollinated by flies breeding on decomposing flowers in Panama. American Journal of Botany 89(3): 527-534. DOI: http:// dx.doi.org/10.3732/ajb.89.3.527

Seemann, B. 1854. The botany of the voyage of H.M.S. Herald. Lovell Reeve. London, UK. Pp. 1-483.

Stern, W. T. 1966. Botanical Latin. History, grammar, syntax, terminology and vocabulary. Hafner Publishing Co. New York, USA. Pp. 1-566.

Thiers, B. (2014, continuously updated). Index Herbariorum: a global directory of public herbaria and associated staff. New York Botanical Garden's Virtual Herbarium; available from: http://sweetgum.nybg.org/ih/ (consultado octubre de 2017).

Vahl, M. 1794. Symbolae Botanicae. Vol. 3. Nicolaus Müller et filius. Copenhagen, Dinamarca. Pp. 1-106.

Wanke, S., F. González y C. Neinhuis. 2006. Systematics of pipevines: Combining morphological and fast-evolving molecular characters to investigate the relationships within subfamily Aristolochioideae (Aristolochiaceae). International Journal of Plant Sciences 167(6): 12151227. DOI: http://dx.doi.org/10.1086/508024. 